\title{
DAI PARTITI AI POLI. LA POLITICA DELLE ALLEANZE
}

\author{
di Aldo Di Virgilio
}

Le elezioni politiche del 27-28 marzo 1994 si sono svolte in un quadro competitivo contrassegnato, rispetto al passato recente, da molteplici novità. Tali novità debbono attribuirsi essenzialmente alla concomitanza e all'intreccio di due fattori, fonte entrambi di incertezza e di (potenziale) trasformazione: (a) il cambiamento della legge elettorale e $(b)$ il prodursi (nell'ultimo biennio) di un rapido quanto imprevisto processo di destrutturazione partitica. Come conseguenza della ridefinizione della struttura dei vincoli e degli incentivi competitivi degli attori (nuova legge elettorale) e/o per effetto del mutamento partitico e della transizione verso equilibri partitici non ben definiti ma sicuramente diversi da quelli tradizionali (processo di destrutturazione), ne è scaturita un'offerta elettorale dalla configurazione per buona parte inedita.

Le due variabili (indipendenti) presentano logiche distinte e un diverso timing. Il nuovo sistema elettorale viene adottato a processo di destrutturazione ormai avanzato. La sua natura di sistema due volte misto - in senso stretto, poiché aggiudica $i$ seggi per tre quarti in base al principio della maggioranza semplice e per un quarto con criterio proporzionalistico; in senso lato, poiché ibrida le due arene (mediante lo scorporo parziale o totale dei voti conseguiti dagli eletti dei collegi uninominali) in modo da rendere $\mathrm{i}$ seggi attribuiti in via proporzionale un elemento di riequilibrio del risultato scaturito in sede maggioritaria - apre agli attori molteplici e sofisticate strategie ${ }^{1}$. La sua

Desidero ringraziare Stefano Bartolini e Roberto D'Alimonte per $i$ loro commenti a una prima versione di questo lavoro e Massimo Bonanni con cui ho discusso alcuni aspetti dello stesso. Ringrazio inoltre Giancarlo Gasperoni dell'Istituto Cattaneo per l'aiuto cartografico. (1993).

1 Un ampio repertorio di tali strategie è discusso da D'Alimonte e Chiaramonte

RIVISTA ITALIANA DI SCIENZA POLITICA / a. XXIV, n. 3, dicembre 1994 
logica operativa, tuttavia, è orientata in prevalenza verso l'aggregazione delle forze e, quindi, la semplificazione dell'offerta elettorale. Per lo più nella direzione opposta è sembrata invece procedere la destrutturazione partitica. Pur costituendo una delle condizioni facilitanti della riforma elettorale ${ }^{2}$, tale dinamica ha visto prevalere le spinte alla disgregazione - con una diversa intensità nei singoli casi e di conseguenza con differenziata incidenza nei singoli schieramenti - e quindi un'ulteriore frammentazione del quadro partitico.

Il punto da fermare è che la concomitanza e l'intreccio di questi due fattori rende difficile «isolare» il loro rispettivo impatto individuale. Pur se le nuove regole di voto hanno finito col determinare in larga parte, all'approssimarsi del passaggio elettorale, la direzione del mutamento partitico in corso, nuovo sistema elettorale e processo di destrutturazione debbono considerarsi, congiuntamente, explanandum della struttura assunta dalla competizione. Questo lavoro esamina pertanto l'adattamento delle forze politiche (vecchie e nuove) al nuovo quadro normativo, alla luce della rapidissima evoluzione dei fattori politici congiunturali. All'interazione fra nuove regole di voto e condizioni politiche di sfondo sono destinate le due sezioni iniziali. La prima presenta un excursus sull'identità in trasformazione degli attori partitici. La seconda analizza il principale fatto nuovo della contesa elettorale: la formazione di coalizioni (i poli elettorali) in grado di presentare candidature unitarie nei collegi uninominali di Camera e Senato. Di queste coalizioni, la terza sezione considera i rapporti fra le unità costitutive e i criteri di regolazione interna. Nella sezione conclusiva, infine, l'attenzione si sposta al quadro aggregato e alla complessiva configurazione dell'offerta elettorale osservata in alcune sue variazioni territoriali.

\section{Dai vecchi ai nuovi partiti}

Nei mesi che precedono le elezioni - fra l'autunno e la primavera - la topografia e la toponomastica del sistema partitico italiano subiscono cambiamenti profondi e radicali. Tre fattori

${ }^{2}$ La destrutturazione può anzi considerarsi, per un verso, una condizione facilitante della riforma elettorale e, per altro verso, un elemento esplicativo dei suoi contenuti più criticabili (Pappalardo 1994). 
concorrono principalmente a questo esito: l'evidenza di un'accresciuta volatilità elettorale, le conseguenze delle inchieste della magistratura sulla corruzione politica, l'adozione di nuove regole elettorali.

Corpose avvisaglie di deallineamento partitico ed elettorale si erano manifestate già all'inizio del decennio. Le elezioni regionali del maggio 1990 e le elezioni politiche dell'aprile 1992, ad esempio, avevano esibito un ragguardevole livello di volatilità del voto, tradottosi in un significativo calo della concentrazione del voto sui primi due partiti e in un accresciuto livello di frammentazione ${ }^{3}$. La compiuta affermazione elettorale della Lega costituisce il principale fattore esplicativo di questa evoluzione $^{4}$. Il suo retroterra permane fortemente territorializzato, peculiarità maggiormente innovativa e potenzialmente dirompente del profilo elettorale del partito del Carroccio, mentre la sua offerta accentua in quella fase l'antagonismo verso le istituzioni e i partiti (Diamanti 1993, 69-85). In quell'avvio di decennio, a questo fenomeno si accompagnano due importanti elementi aggiuntivi. Si tratta dell'uscita di scena di uno dei principali (e strutturalmente del più solido) fra i partiti tradizionali (il Pci), la cui eredità viene contesa da due «nuove» formazioni il Pds post-comunista e il Prc neo-comunista - e della comparsa di un protagonista della successiva destrutturazione: il movimento referendario di Mario Segni.

$\mathrm{Nel}$ passaggio dai vecchi ai nuovi partiti, i successi del Comitato per le riforme elettorali (l'abrogazione referendaria della preferenza multipla nel giugno 1991; le molte adesioni al primo Patto Segni, con cui esponenti di partiti diversi si impegnavano, nella loro qualità di candidati alle elezioni politiche del 1992, a

\footnotetext{
3 Tali indici raggiungono alle elezioni politiche del $1992 \mathrm{i}$ valori maggiori/minori dell'intera storia elettorale repubblicana. Il quantum di volatilità aggregata, ad esempio, è superiore nel 1992 (rispetto al 1987) a quello registrato del passaggio elettorale 19461948. La concentrazione del voto sui primi due partiti, d'altro canto, si colloca per la prima volta al di sotto del $50 \%$ dei voti validi. E l'indice di frammentazione (Rae 1971), infine, cresce a 0.85 , valore anche in questo caso senza precedenti. Per l'impiego di tali indici e per alcuni dati relativi, cfr. Bartolini e Mair (1985, 17-53, 125-146, 340-341) e Corbetta, Parisi e Schadee (1988, 25-62, 399-407, 484-496).

${ }^{4} \mathrm{La}$ Lega lombarda aveva ottenuto alle elezioni politiche del 1987 lo $0,5 \%$ dei voti su scala nazionale, pari al 3,0\% in Lombardia. Nel 1990 conseguiva il 4,8\% sul totale delle 15 regioni a statuto ordinario, l' $8,4 \%$ nelle regioni del Nord (Emilia Romagna compresa) e il $18,9 \%$ in Lombardia. Nel 1992 la forza della Lega era pari al $23 \%$ dei voti validi in Lombardia, al 17,3\% nel Nord (Emilia Romagna compresa) e all'8,6\% su scala nazionale.
} 
sostenere un comune disegno di riforma elettorale; la raccolta delle firme necessarie a presentare tre nuove richieste referendarie in materia elettorale) rivestono una duplice rilevanza. $\mathrm{Ne}$ scaturiva, in primo luogo, un ineludibile vincolo esterno, determinante perché il parlamento superasse un decennale stallo decisionale e licenziasse le due riforme elettorali del 1993 (nel caso della nuova legge elettorale comunale e provinciale «anticipando» un referendum già in calendario; nel caso della nuova legge elettorale per Camera e Senato legiferando a seguito di un pronunciamento referendario). Le iniziative del Corel, in secondo luogo, assumono un carattere programmaticamente «trasversale»: evitano di collocarsi lungo l'asse destra/sinistra, puntano a un «rimescolamento delle carte», finiscono col marcare l'accresciuta disponibilità dell'elettorato a disattendere le indicazioni dei partiti tradizionali e a esprimere un «voto difforme». Questa espressione, coniata proprio all'inizio del decennio (Caciagli e Spreafico 1990), fermava le prime evidenze empiriche e indicava la plausibile prospettiva di una minore rigidità degli allineamenti elettorali e di un progressivo scollamento fra partiti tradizionali e elettorato. Fra le conseguenze più immediate di tali sviluppi si segnalavano, già in quella fase, la maggiore frammentazione del sistema partitico e l'appiattimento della sua configurazione complessiva ${ }^{5}$.

Fino alle elezioni politiche del 1992, il quantum dei fenomeni appena indicati appare ancora modesto, almeno nelle sue dimensioni nazionali6. All'indomani di quel passaggio elettorale, col precisarsi di una formidabile «sfida giudiziaria», il processo in corso sperimenta però un salto di qualità. Le inchieste della magistratura sulla corruzione politica conferiscono infatti al deallineamento partitico i tratti della (repentina e rovinosa) de-

5 Esiti di questa natura suscitavano interrogativi, ormai «preistorici» ma in quel momento politicamente salienti, circa gli effetti che la «secessione» elettorale del Nord avrebbe prodotto rispetto agli equilibri interni alla Dc e, più in generale, alla tenuta della compagine di governo, oppure riguardo alle conseguenze della virtuale scissione del Pci (partito ormai da tempo in declino elettorale) sui rapporti di forza a sinistra, area dove sembrava profilarsi il primato del Psi di Bettino Craxi.

6 In occasione delle elezioni politiche del 1992, i partiti storici ottengono più dell' $80 \%$ dei voti validi, $i$ quattro partiti di governo raggiungono ancora una volta la maggioranza (pur se risicata) di seggi parlamentari, la Dc, pur scivolando al di sotto del $30 \%$ dei voti validi, mantiene una posizione predominante, come si può ricavare dalla disaggregazione dei risultati per la Camera del 1992 secondo $i$ collegi uninominali utilizzati per eleggere la Camera del 1994 che vede la Dc in prima posizione in poco meno dei tre quarti di essi (Camera dei deputati 1994). 
strutturazione. Ne vengono investiti principalmente i partiti di governo e in particolare Dc e Psi, i due maggiori partner delle coalizioni degli anni Ottanta. A seguito di un'interminabile serie di provvedimenti indiziari, tali partiti si ritrovano nell'arco di pochi mesi con vertici politici «decapitati», strutture periferiche disarticolate (e per lo più commissariate e a tesseramento «azzerato»), situazioni debitorie non più oltre sostenibili e, quindi, sedi e apparati in liquidazione. Oltre alle strutture organizzative in senso stretto, le conseguenze delle inchieste giudiziarie investono anche i rapporti fra partiti e istituzioni (diminuita partyness dei governi della XI legislatura) e le relazioni fra partiti e società (esemplare a riguardo la cospicua e costante erosione del seguito elettorale dei partiti di governo in tutte le consultazioni locali parziali svoltesi dopo l'aprile $1992^{7}$ ).

In questo frangente di complessiva de-istituzionalizzazione partitica ${ }^{8}$, l'adozione di regole elettorali di impianto in prevalenza maggioritario favorisce un generale riposizionamento degli attori. Dopo una fase iniziale (1990-1992) caratterizzata dalla rinnovata (pur se malcerta: Ignazi 1992) identità di alcuni partiti tradizionali e dalla comparsa di nuove formazioni (oltre alla Lega, i Verdi e la Rete) e dopo una fase successiva (1992-1993) in cui i partiti tradizionali subiscono, impotenti e ormai in stato confusionale (pur se in alcuni casi ancora «fiduciosi»), l'ostilità crescente di un ambiente esterno assai turbolento, si apriva così un periodo breve ma decisivo di più radicale trasformazione partitica (1993-1994). Vi si consuma la crisi terminale dei «vecchi» partiti e vi si precisa il profilo dei «nuovi» partiti. Rispetto a questo passaggio, la duplice riforma elettorale figura come autonomo e incisivo fattore di trasformazione, secondo un timing che vede gli attori dapprima alle prese con i risultati delle elezioni locali svoltesi con la nuova legge elettorale (giugno e novembre-dicembre 1993) e poi impegnati nelle «grandi manovre» in vista delle elezioni politiche anticipate (la cui data viene fissata in dicembre per l'ultima domenica del marzo 1994).

7 Si tratta delle ultime elezioni comunali e provinciali svoltesi col precedente sistema proporzionale. La Lega vi registra un'ascesa vertiginosa, la Dc vi dimezza i propri consensi, Pds e Msi restano stabili, Psi e partiti laici minori restano presenti a fatica nei consigli rinnovati (dopo aver avuto non poche difficoltà a comporre le liste dei candidati e a raccogliere le firme necessarie a presentarle) (Di Virgilio 1993).

8 Intesa come rovesciamento delle dimensioni dell'istituzionalizzazione indicate da Huntington (1968), precisate e adattate al caso dei partiti da Panebianco (1982). 
Almeno quattro aspetti del voto amministrativo influiscono sulla dinamica partitica che si sviluppa nei tre-quattro mesi che precedono le elezioni politiche del 27-28 marzo. Il voto di lista e l'esito dei ballottaggi per l'elezione diretta dei sindaci indicano: (a) l'emergere di un cleavage nuovo/vecchio che penalizza pesantemente candidati e liste di centro; $(b)$ una certa radicalizzazione dell'elettorato, la cui principale conseguenza, soprattutto nella tornata autunnale, è il dischiudersi di un inedito spazio di mobilitazione a destra, a vantaggio del Msi; $(c)$ lo strutturarsi a sinistra, attorno al Pds, di cartelli elettorali, a diversa geometria, a sostegno di candidature «progressiste» spesso vincenti; (d) l'assenza, in campo moderato, di una analoga capacità di aggregazione, anche per la determinazione della Lega a «correre da sola», evitando ogni sorta di accordo di coalizione (Di Virgilio 1994). Risultati di questo tipo ponevano ai partiti (soprattutto a quelli in maggior difficoltà, ma non solo) stringenti dilemmi politico-strategici e, nonostante le molte differenze fra legge elettorale comunale e legge elettorale per Camera e Senato, assumevano in vista del voto politico un vero e proprio valore pedagogico.

Anche per questo, nei mesi successivi, in un serrato calendario di appuntamenti congressuali e costituenti e parallelamente al precisarsi delle scelte strategiche e delle alleanze elettorali, gli attori tradizionali si scompongono e ricompongono e nuovi attori si affacciano sull'arena politica. Epicentro del sommovimento è l'area compresa fra Lega e Pds, squassata dalle vicende giudiziarie e dai risultati elettorali. Nella sua faticosa trasformazione in Partito popolare, la Dc - che aveva subito dapprima la defezione di Leoluca Orlando e della Rete, poi, con ben altre conseguenze, l'uscita di Segni e dei Popolari per la Riforma, infine la presa di distanza degli intellettuali del gruppo dei Cristiano sociali - esce di scena dividendosi in due tronconi: al Ppi, che nasce senza risolvere le antiche e laceranti contrapposizioni interne fra sinistra e settore moderato, si contrappone il Centro Cristiano Democratico, in cui si ritrova parte del centro ex doroteo. Il Psi, dal canto suo, è teatro di una diaspora politica. La segreteria Del Turco, fino a poco prima pronta a sostenere Segni nel quadro di una (indefinita) alleanza di centro-sinistra, dopo la tornata amministrativa autunnale si orienta verso sinistra, puntando sul rapporto (da minore a maggiore) col Pds le sue ultime chances di sopravvivenza politica. Pure a sinistra si colloca il movimento di Rinascita socialista, in cui si erano rac- 
colti i sostenitori di Giorgio Benvenuto, uscito dal Psi dopo la crisi della sua breve segreteria. Ostile all'accordo col Pds è invece la «vecchia guardia» craxiana, che conta buona parte di un gruppo parlamentare privo ormai di prospettive politiche'. Ancora diversa è la strada dei socialisti vicini a Amato, che si collegano organicamente a Segni, mentre altri esponenti del partito - a completare la diaspora - si associano a Alleanza democratica (Ruffolo) o al nascente movimento di Silvio Berlusconi (Sacconi). Il risultato del voto amministrativo e la preparazione delle elezioni politiche, infine, polarizzano i partiti laici minori. Nel caso di Pri e Pli, ad esempio, alle componenti che restano ancorate al centro (i repubblicani di La Malfa e i liberali di Zanone e Patuelli) si contrappongono $i$ gruppi in fuga, rispettivamente, verso sinistra (i repubblicani entrati in Alleanza democratica) o verso destra (l'Unione di Centro di Costa e di Biondi, collegata a Berlusconi). Il successo elettorale ottenuto in sede locale e le opportunità aperte dalla crisi democristiana creano fermento anche in casa missina, dove Fini lancia Alleanza nazionale, aggregazione che si pretende più capiente, articolata e moderata del Msi. Il nuovo raggruppamento raccoglie in realtà l'adesione di un numero limitato di «esterni» (personalità moderate come Fisichella, ex esponenti democristiani come Fiori e Selva), ma diventa l'efficace strumento della leadership missina, la cui ambizione è essenzialmente assicurare piena legittimazione alla destra.

Fra la tornata amministrativa autunnale e le elezioni politiche di marzo si stabilizza anche il profilo di tre nuove formazioni. Si tratta di Alleanza democratica, del Patto Segni e di Forza Italia. Com'è spesso proprio delle fasi di transizione, tali attori vivono molte stagioni in un arco di tempo assai breve. Il progetto di dar vita a un'Alleanza democratica, formulato sull'onda dei successi del movimento referendario e del procedere della crisi dei partiti tradizionali ${ }^{10}$, puntava a creare, sin dall'inizio

${ }^{9}$ La divaricazione nel gruppo parlamentare socialista della Camera provoca, negli ultimi mesi della legislatura, una scissione di fatto con l'elezione di due capigruppo (Capria, in linea con la segreteria; Piro, sostenuto dalla «vecchia guardia»). Gli avversari di Del Turco - il quale a gennaio cancella dal simbolo del partito il garofano craxiano danno vita a movimenti scissionisti quali la Federazione liberalsocialista e l'Unione dei democratici e dei socialisti.

${ }^{10}$ La prima uscita ufficiale di Alleanza democratica (che si presenta in quella fase come soggetto politico ancora cosituendo e quindi con l'appellativo di «Verso Alleanza democratica») è dell'ottobre 1992 e punta a unificare e rilanciare forze laiche, cattoliche 
della XI legislatura e con il sostegno di una robusta copertura giornalistica, un'aggregazione in grado di interpretare il «nuovo» e di dialogare col Pds, eventualmente «assorbendolo». Per tappe successive, connesse alla disponibilità soltanto intermittente del $\mathrm{Pds}$ (e alle resistenze del suo apparato), alla rottura dell'intesa con Segni (di cui Alleanza democratica non approva la ri-conversione all'opzione centrista), all'ostilità di altre componenti della sinistra (Rifondazione comunista, la Rete, una parte dei Verdi), le ambizioni e le prospettive di Ad, nonostante $i$ successi ottenuti in sede locale ${ }^{11}$, si ridimensionano. Incapace di affermarsi come fattore di dinamismo e di innovazione, Ad si caratterizza così come sponda destra dell'area di sinistra e orienta la sua azione verso interessi di tipo partigiano, in primo luogo il successo elettorale del proprio gruppo dirigente.

Non dissimile è per certi versi la parabola politica di Segni. Dopo l'uscita dalla Dc (29 marzo 1993) e il referendum del 18 aprile sulla legge elettorale del Senato, Segni sembra infatti poter aggregare attorno a sé e ai suoi Popolari per la riforma quell'area moderata orfana ormai dei suoi referenti politici tradizionali (a quel punto scomparsi o ripudiati). Il leader referendario si rivolge invece verso sinistra, si associa ad Ad, dialoga col Pds, si dichiara avversario irriducibile della Lega. Prima della tornata amministrativa autunnale, però, si distacca da Ad pur appoggiandone i principali candidati alla mayorship, rompe con il Pds, cerca l'alleanza della Lega, per poi tornare, sui propri passi, all'accordo di centro con il Ppi di Martinazzoli.

Questo percorso altalenante è uno dei tasselli decisivi del puzzle delle alleanze e, oltre a spiegare perché in pochi mesi Segni disperda momentum e credibilità, esemplifica assai bene la fluidità della congiuntura politica. L'apertura a sinistra dell'estate segnala la priorità accordata da Segni al rapporto con un $\mathrm{Pds}$ che in quel momento, dopo essere stato convinto sostenitore dei referendum del Corel, appariva il probabile vincitore delle future elezioni politiche e, crollati Dc e Psi, il nuovo perno del sistema. In quella stessa fase, Segni condivide inoltre con la sinistra una politica del «cordone sanitario» nei confronti della Lega e delle sue proposte secessioniste - cui del resto cor-

e socialiste, individuando come personalità in grado di assicurare la transizione dai vecchi ai nuovi assetti Segni, La Malfa e Martelli.

${ }_{11}$ Alleanza riesce, ad esempio, a conquistare la poltrona di sindaco a Torino (Castellani) e Catania (Bianco) a giugno e a Roma (Rutelli) e Genova (Sansa) a dicembre. 
risponde l'ostilità del Carroccio contro tutti-gli-altri. La renitenza a scegliere il campo moderato, nonostante l'area alla sinistra del centro si caratterizzi per una già cospicua densità partitica (numerosità degli attori, consistenza delle risorse politico-organizzative da essi dispiegate), si spiega infine con la convinzione che esso sia, tutto sommato, elettoralmente penalizzante. Su tutt'altre premesse si gioca invece, nell'autunno, la ricerca di un accordo con la Lega e il successivo accordo col Ppi. Dopo aver sperimentato quanto stretto fosse il suo margine di manovra a sinistra, Segni punta sulla Lega per due ragioni principali. In primo luogo, dopo che la tornata amministrativa autunnale aveva evidenziato $i$ limiti dell'autarchia competitiva in consultazioni di impianto maggioritario, la Lega, per la prima volta in difficoltà, si trova nell'assoluta necessità di stringere alleanze (e di rendere quindi meno oltranziste e più negoziabili le proprie posizioni). In secondo luogo, l'eventuale accordo con la Lega avrebbe potuto far recedere Silvio Berlusconi - a quel momento diretto e temibile concorrente di Segni al ruolo di rassembleur del campo moderato - dal proposito di «entrare» in politica. In questo «peregrinaggio», che si conclude, dopo il fallimento dei due obiettivi appena indicati, con l'accordo al centro col Ppi, Segni resta collegato ad alcuni esponenti dell'area laica - Amato, Zanone e, con minore continuità, La Malfa -, coi quali dà vita al Patto Segni, compagine dai confini più ampli rispetto ai Popolari per la riforma.

A due mesi dal voto si chiarisce in via definitiva anche la posizione di Berlusconi, il quale ufficializza a fine gennaio la sua intenzione di voler partecipare direttamente alle elezioni e presenta il suo nuovo movimento ${ }^{12}$. Alla testa di un gruppo imprenditoriale rimasto privo di interlocutori politici a seguito della destrutturazione del centro partitico tradizionale e fortemente osteggiato a sinistra soprattutto per le sue attività nel settore editoriale e dell'informazione, Berlusconi aveva sollecitato sin dall'estate 1993 un accordo fra le forze moderate in opposizione al nascente cartello delle sinistre. A questo ruolo di suggeritore (esterno) di un'alleanza che tarda a concretarsi, Berlusconi alterna quello di leader «naturale» di una nuova forza po-

12 Il 26 gennaio 1994, le reti Fininvest teletrasmettono una cassetta video di circa dieci minuti con cui Berlusconi annuncia il suo proposito. Il 6 febbraio, in occasione della prima uscita pubblica di Forza Italia, Berlusconi presenta il programma del suo movimento. 
litica. Differisce però la scelta dell'impegno diretto in prima persona e le sue iniziative rimangono sospese, per alcuni mesi, fra l'ambito aziendale (preparare il gruppo Fininvest al possibile confronto con un governo ostile) e l'azione politica in senso stretto (che avrebbe trasformato l'imprenditore lombardo in imprenditore politico: Diamanti 1994). Nell'incertezza prepara con cura il suo «possibile» ingresso nell'arena elettorale sulla base di una strategia coalizionale caratterizzata, tanto nella fase genetica quanto nella fase operativa, dal trasferimento sul terreno politico di criteri organizzativi (e di risorse umane) sperimentati con successo in sede aziendale ${ }^{13}$.

Alla vigilia delle elezioni politiche di marzo, si delineano così assetti partitici assai diversi rispetto alla configurazione di pochi anni prima ( $\mathrm{Tab}$. 1). Il quadro si presenta più affollato (si può leggere nella tabella 1 come l'eredità dei sette partiti tradizionali venga raccolta da un numero più che doppio di formazioni politiche) e, in attesa del chiarimento elettorale, ancora confuso. L'accresciuta frammentazione partitica, aspetto ricorrente nei momenti di transizione, è in parte bilanciata dalle nuove regole di voto che inducono una parziale, ancorché fragile, ricomposizione. L'applicazione, entro un quadro multipartitico, di un sistema elettorale fondato in prevalenza sul principio della maggioranza semplice sollecita infatti gli attori verso strategie elettorali di tipo cooperativo e quindi, in concomitanza con il passaggio dai vecchi ai nuovi partiti, verso la formazione di coalizioni. Trattandosi di alleanze definite per lo più a poche settimane dal voto, i poli elettorali si caratterizzano come forme d'aggregazione deboli. La loro presenza semplifica però, almeno in parte, il quadro partitico e lascia emergere un'inedita logica di schieramento che va ad aggiungersi alla preesistente logica partitica.

13 L'ambigua condotta di Berlusconi corrispondeva, oltre all'esigenza di calamitare l'attenzione dei mezzi di informazione e dell'opinione pubblica, anche a un conflitto interno al gruppo Fininvest fra sostenitori della strategia aziendale e fautori del lancio in politica (per una ricostruzione giornalistica, dichiaratamente «antipatizzante», della «scesa in campo» dell'imprenditore lombardo, cfr. Corrias, Gramellini e Maltese 1994). Tali incertezze non avevano impedito a Massimo dell'Utri, amministratore di Publitalia, di procedere già dal settembre 1993, mediante tecniche aziendalistiche, alla selezione di candidati virtuali, di un partito non ancora esistente, in vista di elezioni che a quel momento non avevano ancora una data certa. 
TAB. 1. Dai vecchi ai nuovi partiti
vecchi partiti
nuovi partiti
(anni Ottanta)
(anni Novanta)

partiti tradizionali:

Dc $\quad$ Partito popolare italiano (Martinazzoli, Buttiglione, Bindi) (gennaio 1994)

Centro cristiano democratico (Mastella, D’Onofrio, Casini)

(gennaio 1994)

Alleanza nazionale (Fiori, Selva) (gennaio 1994)

Pci $\quad\left\{\begin{array}{l}\text { Pds (gennaio 1991) } \\ \text { Rc (febbraio 1991) }\end{array}\right.$

Rete-Movimento democratico (Novelli) (1991)
Rinascita socialista (Mattina, Benvenuto) (giugno 1993)
Psi Patto Segni (Amato) (giugno 1993)
Ps (Del Turco) (gennaio 1994)
Federazione liberal-socialista - Unione dei Democratici e dei
Socialisti (Boniver, Intini, Piro) (autunno 1993)

Msi-Dn Msi-Alleanza nazionale (gennaio 1994)

Pri $\begin{cases}\text { Pri (La Malfa) } \\ \text { Alleanza democratica (Bogi, Visentini) }\end{cases}$

Pli $\left\{\begin{array}{l}\text { Pli }- \text { Federazione dei liberali (Zanone, Patuelli) } \\ \text { Unione di centro (Biondi, Costa) (autunno 1993) } \\ \text { Alleanza democratica (Battistuzzi) }\end{array}\right.$

Psdi $\quad\{\quad$ Unione dei Democratici e dei Socialisti (Ferri)

Alleanza democratica

nuove formazioni:

Partito radicale Liste Pannella (1992) - Riformatori (1994)

$\left.\begin{array}{l}\text { Liga Veneta (1983) } \\ \text { Lega Lombarda (1987) }\end{array}\right\}$ Lega Nord (1991)

$\left.\begin{array}{l}\text { Verdi sole che ride (1985) } \\ \text { Verdi arcobaleno (1987) }\end{array}\right\}$ Verdi (dicembre 1990)

Forza Italia (febbraio 1994) 
La genesi delle alleanze: sinistra, destre, centro

Le forza politiche indicate nella tabella 1 - le maggiori come le minori, le moderate come le più estreme, quelle a diffusione nazionale come quelle a radicamento territorializzato entrano tutte (o quasi) a far parte di coalizioni elettorali (tab. 2). Al momento del deposito delle candidature (21 febbraio), ciascuna di tali coalizioni è presente nei collegi uninominali, salvo eccezioni, con un proprio, unico candidato.

In tal modo gli attori rispondevano al primo e principale dilemma competitivo posto dal nuovo sistema elettorale: quale strategia adottare nei collegi uninominali (in cui si sarebbero eletti 475 deputati e 230 senatori). Ad esso se ne aggiungeva per lo meno un secondo, relativo all'arena proporzionale (in cui si distribuivano 155 seggi per la Camera e 83 per il Senato) e interconnesso al precedente per via del previsto collegamento fra candidato e simboli partitici (e del relativo meccanismo dello scorporo). Questo secondo dilemma si articolava per le forze minori in una scelta ulteriore legata alla soglia di rappresentanza. Le differenze fra la normativa elettorale per la Camera e quella per il Senato, infine, richiedevano agli attori possibili specificazioni strategiche (connesse alle diverse modalità di espressione del voto - scheda doppia o scheda unica -, al diverso tipo di scorporo - parziale o totale -, alla diversa qualità della soglia di rappresentanza - esplicita e nazionale per la Camera, implicita e circoscrizionale per il Senato). Ma si consideri, per il momento, il processo di formazione delle coalizioni elettorali.

Esaminare la genesi delle alleanze consente di fissare le tappe salienti del processo di selezione delle strategie elettorali degli attori e di valutare quindi la loro (differenziata) capacità di adattamento al cambiamento delle regole di voto. Gli aspetti costitutivi, inoltre, sono propedeutici alla definizione delle concrete modalità di accordo e dei criteri di regolazione prevalenti in ciascuna coalizione. In sede analitica è infatti utile tenere distinti tre diversi livelli negoziali e di scelta attorno ai quali si articola la convergenza delle diverse forze politiche nelle varie alleanze: (a) una preliminare intesa di base, ovvero la generica disponibilità politica dei contraenti a convergere in uno stesso polo elettorale; $(b)$ un accordo programmatico di governo cui tale intesa può dare origine; (c) un accordo sulle scelte di natura tecnico-elettorale in cui l'intesa deve necessariamente esplicitar- 
si. Quest'ultimo punto, cruciale nella fase negoziale infracoalizionale, combina, più specificamente, aspetti quantitativi (quan$t i$ collegi assegnare alle diverse componenti del polo; come definire il collegamento fra candidato e simboli partitici, influente, attraverso lo scorporo, sulla ripartizione dei seggi proporzionali) e qualitativi (quali collegi - «sicuri» o «marginali» - assegnare alle diverse componenti del polo e a quali candidati - «forti» o «deboli», «candidati-apparato» o «candidati-espressione della società civile» -, aspetto, quest'ultimo, che può rientrare nella trattativa oppure esserne escluso e delegato all'autonoma decisione delle singole componenti).

Nel caso concreto, il processo di formazione delle coalizioni e di definizione degli accordi costitutivi di ciascuna alleanza si presenta assai articolato e spesso macchinoso. La fase genetica appare contrassegnata da uno squilibrio di fondo, evidente già nelle elezioni locali dell'estate e dell'autunno 1993: il «naturale» profilarsi di una coalizione elettorale di sinistra (i Progressisti) e l'assenza di una coalizione alternativa.

A sinistra il riflesso unitario e la volontà di definire un accordo di schieramento che consentisse la presentazione di un'unica candidatura «progressista» in ciascun collegio uninominale si manifestano piuttosto in anticipo. Molteplici condizioni convergevano verso questa soluzione. Un primo fattore era la presenza nello schieramento di un partner aggregante, dotato di risorse organizzative comparativamente ragguardevoli - il Pds -, assai determinato all'accordo e a svolgere nell'ipotetico cartello elettorale il ruolo di perno centrale, anche a costo di concessioni ai partner (minori). La formazione di una coalizione elettorale era favorita, in secondo luogo, dallo stesso elevato numero di partiti collocati a sinistra (otto: Tab. 2) e dal fatto che, con l'eccezione del Pds, si trattasse di formazioni minori. Se ciò rendeva il tavolo negoziale defatigante e l'accordo soggetto ai veti incrociati dei partner, scoraggiava però gli attori dal «correre da soli», a meno che non fosse a puri scopi di disturbo. Vi era, infine, il precedente delle elezioni locali del 1993, in cui la convergenza a sostegno di candidature comuni alla carica di sindaco aveva consentito alla sinistra, pur se in una congiuntura competitiva assai favorevole, la conquista del governo di molte città.

Rispetto a quella precedente esperienza, la strategia elettorale della sinistra presentava peraltro, in occasione delle elezioni politiche, una differenza di fondo, le cui implicazioni hanno in- 
fluenzato la formazione del cartello progressista. Alla diversificazione territoriale delle coalizioni municipali - la cui variegata geometria si fondava anche sul differenziato profilo dei relativi candidati alla carica di sindaco - ha infatti corrisposto l'omogeneità territoriale dell'alleanza per l'elezione di Camera e Senato. Questa scelta finisce con l'«ingessare» la coalizione, negandole quella flessibilità territoriale che le prerogative del sistema elettorale e il contesto partitico di applicazione avrebbero dovuto suggerire. Fondandosi sul principio «nessun nemico a sinistra», la scelta dell'omogeneità territoriale della coalizione accresce in secondo luogo l'influenza delle componenti più radicali dello schieramento (la sinistra antagonista - Rifondazione comunista, Rete, parte dei Verdi - la cui presenza avrebbe potuto essere «sdrammatizzata» se ricondotta entro ambiti locali) e vanifica la possibilità di estendere l'alleanza in direzione del centro (con l'unica eccezione della candidatura di Claudio Magris nel collegio senatoriale di Trieste e delle candidature di centro-sinistra Aggregazione democratica autonomista in Alto Adige). L'assenza di frontiere a sinistra, inoltre, rende problematica la definizione dei confini dell'alleanza anche sul fianco destro. La questione, affrontata una prima volta nell'estate del 1993 in relazione alla temporanea e non ben definita associazione di Segni allo schieramento di sinistra, si pone soprattutto dopo il test amministrativo autunnale, a seguito dell'opposizione della componente «giustizialista» dello schieramento (la Rete in primo luogo e, in parte, anche i Verdi) alla presenza dei socialisti di Del Turco e dei repubblicani di La Malfa nella coalizione ${ }^{14}$. Con la mediazione del Pds, il Psi è infine accettato come partner a pieno titolo, mentre La Malfa, a quel punto, si accorda con Segni. Il cartello progressista affida in tal modo all'esile Alleanza democratica (peraltro contestata anch'essa, da Rifondazione comunista e dai Verdi, in particolare sul terreno delle politiche economiche) e, in fin dei conti, direttamente al Pds la propria

${ }^{14}$ La Rete intendeva con ciò riaffermare all'interno del polo progressista la «questione morale» e il principio che nessun esponente politico indagato dalla magistratura dovesse occupare cariche partitiche o rappresentative né essere candidato alle elezioni. Tale questione venne sollevata a proposito della posizione di La Malfa, ma il leader della Rete Orlando dichiarò in più occasioni - ad esempio in margine alle ricorrenti voci di un diretto coinvolgimento di Occhetto e di D'Alema nell'inchiesta «mani pulite» che si trattava di una regola inderogabile e che non tollerava eccezioni. Quanto ai socialisti di Del Turco, le riserve della Rete si fondavano su un abiura del passato craxiano ritenuto tardivo e insufficiente. 
proiezione verso il centro e finisce così con l'occupare uno spazio in definitiva non molto più esteso di quello frontista.

Assai più laboriosa è la definizione delle alleanze e delle strategie elettorali nell'area non-di-sinistra. Di fronte alla relativa facilità con cui si costituisce il cartello «progressista», la formazione delle alleanze alternative si presenta come un vero e proprio rompicapo, la cui soluzione si precisa, a poche settimane dal deposito delle candidature e sotto l'ineludibile pressione del trascorrere del tempo, non nella chimerica, benché da molti

ТАВ. 2. La composizione delle coalizioni elettorali

coalizioni $\quad$ partner partitici

SINISTRA

«Progressisti» $\quad\left\{\begin{array}{l}\text { Rifondazione Comunista } \\ \text { Rete-Movimento democratico } \\ \text { Verdi } \\ \text { Partito Democratico della Sinistra } \\ \text { Rinascita Socialista } \\ \text { Partito Socialista } \\ \text { Alleanza Democratica } \\ \text { Cristiano sociali }\end{array}\right.$

CENTRO

«Patto per l'Italia» $\left\{\begin{array}{l}\text { Partito Popolare Italiano } \\ \text { Patto Segni }\left\{\begin{array}{l}\text { Popolari per la riforma } \\ \text { Partito repubblicano (La Malfa) } \\ \text { socialisti (Amato) } \\ \text { liberali (Zanone) }\end{array}\right.\end{array}\right.$

DESTRA

«Polo delle libertà» $\left\{\begin{array}{l}\text { Forza Italia } \\ \text { Unione di Centro } \\ \text { Centro Cristiano Democratico } \\ \text { Polo liberaldemocratico } \\ \text { Lega nord } \\ \text { [Riformatori] }\end{array}\right.$

«Polo del buongoverno» $\left\{\begin{array}{l}\text { Forza Italia } \\ \text { Unione di Centro } \\ \text { Centro Cristiano Democratico } \\ \text { Polo liberaldemocratico } \\ \text { Msi-Alleanza Nazionale } \\ \text { [Unione dei democratici e dei socialisti] }\end{array}\right.$ 
auspicata, coalizione moderata (o «liberaldemocratica»), bensì nella forma di tre alleanze distinte, due a destra, a diversa geografia e geometria (il Polo delle libertà e il Polo del buon governo), e una al centro (il Patto per l'Italia) (Tab. 2).

Il timing della genesi di tali alleanze è segnato, lo si è già detto, dalle elezioni amministrative autunnali. Prima di quel risultato, l'area moderata - che in quella fase sembra riferirsi a Segni, Amato e Martinazzoli e di cui un Berlusconi ancora (ufficialmente) lontano dall'impegno diretto si presenta come il più acceso (ma non richiesto) promotore - appare orientata a convergere in un'aggregazione di tenore giscardiano, ancorata al centro, che escluda la Lega - salvo lasciar aperta la possibilità di eventuali, limitati accordi di collegio - e che neppure si pone la questione dei rapporti con la destra missina. Dopo quel risultato, i presupposti di tale operazione risultano radicalmente modificati. Il crollo del centro nei ballottaggi per l'elezione dei sindaci, il successo delle liste e delle candidature missine, il bisogno di alleanze della Lega si impongono come nuovi e decisivi aspetti della situazione.

Queste nuove coordinate modificano sensibilmente la posizioni degli attori e segnano la fase negoziale successiva. Il risultato amministrativo, ad esempio, scatena dentro la Dc forti spinte centrifughe. Oltre a non consentirle di evitare la scissione prima di raggiungere l'approdo del Partito popolare, ciò la relega, per tutta la fase successiva, a un ruolo di secondo piano, che Martinazzoli interpreta, non senza abilità, affidandosi a una linea negoziale fondata sull'immobilismo. Il crollo del centro e le aperture della Lega, in secondo luogo, rendono assai meno rigido il confine tracciato, in precedenza, a dividere l'area moderata dalla Lega. A debite condizioni, Segni e i suoi alleati laici si dichiarano disposti a estendere al Carroccio le trattative per la formazione di un'aggregazione moderata, mentre Bossi reclama a più riprese la sua appartenenza all'area liberal-democratica. È tuttavia il successo della destra missina a indurre gli sviluppi più significativi e meno prevedibili. Con l'obiettivo di stabilizzare i successi appena ottenuti e di accreditarsi come competitore pienamente legittimo, il Msi, per iniziativa di Fini, accelera la propria trasformazione in Alleanza nazionale. Tale operazione trova il pieno appoggio di Berlusconi, che allo «scongelamento» della destra elettorale punta come risorsa primaria della sua strategia competitiva (a cominciare dalla risoluzione dello stallo, di cui lo stesso Berlusconi era stato interessa- 
to spettatore, in cui l'area moderata versava ormai da mesi). Com'era già emerso al ballottaggio fra Fini e Rutelli per l'elezione del sindaco di Roma ${ }^{15}$, tale opzione suscitava polemiche e ostilità, poiché revocava in dubbio, o comunque dichiarava politicamente obsoleto, uno dei principali «miti fondanti» della Repubblica - il cleavage fascismo-antifascismo. Pur riferendosi all'apertura verso Fini - che preludeva a un accordo politico destinato a durare - con la prudente etichetta di «intesa elettorale a carattere tecnico», Berlusconi in realtà scommetteva con questa scelta sul fatto che la «solidarietà antifascista», così presente a livello di élites (politiche e culturali), non costituisse più per l'elettorato di massa un elemento altrettanto discriminante e che gli attacchi ricevuti a riguardo potessero risolversi in un elemento mobilitante a proprio favore.

Alla legittimazione della destra, Berlusconi affianca nella costruzione della sua strategia elettorale, come secondo atout competitivo, la differenziazione territoriale delle alleanze. Riesce così a formare due coalizioni distinte, a geografia variabile - al Sud, assieme all' Alleanza nazionale, il Polo del buon governo; al Nord, assieme alla Lega, il Polo delle libertà - delle quali, per la dichiarata incompatibilità fra i suoi due principali partner ${ }^{16}$ e per la loro connotazione di attori fino a quel momento marginali e territorializzati, costituisce l'elemento unificante che «[permette] a una destra "regionalizzata" di penetrare e di muoversi in un mercato nazionale» (Diamanti e Mannheimer 1994, VII). Sulla base di due formidabili intuizioni strategiche l'apertura a destra e la differenziazione territoriale delle alleanze -, Berlusconi decide quindi di impegnarsi in prima persona, con Forza Italia, nell'arena elettorale e di proporsi, in alternativa a Segni, come personalità aggregante del polo moderato.

L'alterità fra Berlusconi e Segni si rende evidente in margi-

15 In quell'occasione Berlusconi dichiarò le proprie simpatie per Fini, affermando che gli elettori romani che lo sostenevano non erano certo (tutti) fascisti, bensì soprattutto avversari della sinistra. Le sue dichiarazioni vennero riprese con grande evidenza e per lo più duramente censurate dagli organi di informazione (compresi quelli, a stampa o teletrasmessi, dei quali Berlusconi era l'editore).

${ }^{16}$ La chiusura muove peraltro più dalla Lega che non dal Msi che, dopo il voto amministrativo dell'autunno 1993 e in preparazione dell'Alleanza nazionale, aveva rivolto alla Lega una proposta di accordo su base territoriale rimasta senza risposta. Sul piano sostantivo, la contrapposizione fra queste due destre investiva aspetti decisivi, dall'assetto amministrativo e istituzionale dello stato, al peso e al ruolo del settore economico pubblico, alle politiche per il Mezzogiorno. 
ne alle trattative che ciascuno dei due conduce con la Lega. L'annuncio dell'intesa fra Segni e Maroni ${ }^{17}$, sconfessata dal leader della Lega Umberto Bossi a ventiquattr'ore dalla firma (24 gennaio), rappresenta, in questa prospettiva, un decisivo punto di svolta nella formazione delle aggregazioni moderate. L'«infortunio» negoziale ridimensiona definitivamente l'immagine di Segni, il quale - incapace di scostare il Ppi dal suo immobilismo, di apparire sufficientemente convincente alla Lega, di scoraggiare Berlusconi dai suoi propositi «interventisti» vede seriamente compromessa qualsiasi possibilità di attivare una logica di schieramento. Per la Lega si tratta invece dell'escamotage con cui dare via libera all'accordo con Berlusconi e ottenere per sé, in uno stesso tempo, almeno tre importanti risultati: rompere un temuto «accerchiamento» (la possibilità che Segni e Berlusconi finissero con l'accordarsi fra loro, magari col benestare di Martinazzoli), evitare collegamenti elettorali con il Ppi erede della Dc (al rischio di appannare la propria diversità), far valere il proprio potere contrattuale alleandosi (non senza diffidenze) con l'interlocutore disposto a concedere di più. A quel punto, Segni ripiega, con i suoi alleati laici, su un'intesa al centro coi popolari di Martinazzoli - il Patto per l'Italia - che, stretta nei collegi uninominali dalle aggregazioni delle sinistre e delle destre, raggiunge a malapena la massa critica del polo. Berlusconi, dal canto suo, riesce a raccogliere attorno a sé, come componenti minori dello schieramento di destra, i centristi liberali, i centristi cristiano-democratici e la pattuglia di pattisti dissidenti riuniti da Teso e Usiglio nel Polo liberaldemocratico - i quali, ben disposti a un accordo con la Lega e guadagnati senza troppe difficoltà all'ipotesi di un fronte moderato senza confini a destra, fanno parte di entrambe le coalizioni nonché, limitatamente a un certo numero di collegi del Nord, i riformatori di Pannella.

Queste quattro alleanze elettorali, nate in breve tempo e in una fase di mutamento partitico, poco coese e fondate per lo

17 L'accordo si configurava come un protocollo programmatico preliminare alla definizione dell'intesa politica e elettorale vera e propria, siglato oltre che da Segni e Maroni anche da Rocco Buttiglione, che aveva presenziato alla trattativa in rappresentanza di Martinazzoli e del Ppi. L'accordo programmatico si soffermava sul riconoscimento dell'intangibilità dell'unità politica del paese, su una riforma istituzionale in senso federalista abbinata alla legittimazione diretta dell'esecutivo (elezione del premier), su politiche economiche e fiscali di rigore. 
più sulle convenienze strategiche dei singoli attori anziché su convergenze di carattere programmatico, si presentano agli elettori non tanto come squadre di governo fra loro alternative quanto come vere e proprie «ammucchiate» (Sartori 1994). La dimensione programmatica di governo è esile a sinistra - dove si tende a «sdoppiare» il tavolo progressista, distinguendo fra alleanza elettorale e alleanza di governo -, assente a destra dove le intese raggiunte hanno un carattere prioritariamente elettorale -, più solida al centro - dove però, in assenza della vocazione maggioritaria che definisce l'ambizione politica del polo, si trovava subordinata all'ipotesi di un parlamento privo di maggioranza, in cui il centro potesse proporsi come ago della bilancia.

\section{Dentro le coalizioni: il «come» e il «dove» delle alleanze}

L'applicazione di un sistema maggioritario a un turno in un contesto a multipartitismo estremo favorisce dunque, lo si è appena visto, la formazione di alleanze elettorali. Nei collegi uninominali (tendenzialmente in tutti se, come per la sinistra e per il centro, l'alleanza è nazionale; in una parte di essi quando, com'è nel caso delle destre, si tratta di alleanze macroregionali) ciascuna aggregazione presenta un proprio candidato. Un'offerta politica di questo tipo implica, dentro ciascuna alleanza, un processo negoziale per l'attribuzione dei collegi a ciascuna componente e per la selezione dei relativi candidati. L'accordo che ne scaturisce configura una divisione preventiva di spoglie elettorali ipotetiche. Si tratta di un accordo che soggiace all'alea del risultato elettorale - la territorializzazione del voto compensando soltanto in parte il ridursi del numero di collegi sicuri connesso all'accresciuta volatilità e alla fase di transizione partitica - e che sottrae all'elettore possibilità di scelta che altri meccanismi elettorali sarebbero stati invece in grado di assicurare ${ }^{18}$.

18 È il caso ad esempio del doppio turno e, in particolare, del doppio turno utilizzato per l'elezione dei deputati all'Assemblea nazionale francese (in cui l'accesso al secondo turno è aperto a quei candidati che superano la soglia di esclusione, anziché chiuso ai due candidati di testa). Questa variante lascia agli elettori il compito di pronunciarsi sui candidati dei singoli partiti, in un primo turno trasformato in una sorta di primaria di schieramento. La logica maggioritaria del sistema - rafforzata in modo decisivo, nel caso della Quinta Repubblica, dal circuito elettorale presidenziale e dal suo impatto sul sistema partitico - favorisce, al secondo turno, confronti bipolari. A seguito 
La considerazione di questo tipo di accordi, e più specificamente delle modalità negoziali prevalenti in ciascun «tavolo» delle trattative, consente di ricavare utili informazioni sui rapporti esitenti all'interno delle singole «famiglie politiche» e di far luce sulle scelte di natura tecnico-elettorale che, come si è detto, costituiscono un livello necessario dell'accordo costitutivo delle aggregazioni elettorali.

A sinistra, l'elevato numero degli attori, la densità partitica dello schieramento, la pluralità di sedi negoziali hanno reso la trattativa laboriosa e contrastata, nonostante l'assodata e (quasi) «naturale» disponibilità delle forze politiche interessate a convergere in una medesima aggregazione. La presenza di otto attori ha reso la trattativa preda di un potere di veto diffuso, connesso alla pari dignità negoziale accordata, almeno formalmente, a ciascuno di essi. Il riproporsi di situazioni di stallo è stato inoltre alimentato dall' «affollamento» dello schieramento, arena in cui si confrontavano le divergenti pressioni di quadri e apparati di ciascuna componente e le contrastanti ambizioni degli «entranti» e degli «uscenti». Il processo negoziale, infine, è risultato appesantito dall'elevato numero di sedi e canali negoziali. I livelli orizzontali ( $\mathrm{i}$ «tavoli» e i partiti regionali) hanno in generale prevalso sulle istanze verticali (il «tavolo» nazionale; $i$ partiti centrali). Queste ultime, tuttavia, si sono riservate la libera allocazione di una quota di candidature «nazionali», comprendenti anche $\mathrm{i}$ principali leader delle componenti minori e più deboli dello schieramento, «paracadutati» dal centro verso collegi sicuri, e si sono imposte, quasi sempre con successo ${ }^{19}$, come sede ultima di risoluzione dei contrasti negoziali maturati in sede regionale. Queste modalità decisionali hanno moltiplicato le occasioni di conflitto, ma disperso al tempo stesso le linee

di accordi per lo più nazionali, i candidati peggio piazzati di ciascun schieramento desistono infatti dalla corsa, pur potendo in principio mantenervisi, a favore di quelli in miglior posizione. Il doppio turno utilizzato per l'elezione dei deputati dell'Assemblea nazionale francese non preclude la possibilità di accordi preventivi - basati sulla rinuncia di un partito maggiore a presentare in determinati collegi propri candidati per favorire un alleato minore (e moderato), come è accaduto a lungo in Francia fra Ps e Mrg (e come avrebbe potuto essere nelle elezioni di marzo fra $\mathrm{Pds}$ e Ad) - e riduce il peso delle componenti più radicali di schieramento, come indicano i rapporti fra Ps e Pcf (e come sarebbe nei rapporti fra Pds e Rc).

19 Uno dei pochi esempi di prevalenza del livello regionale su quello nazionale è stato il diniego del tavolo progressista della Toscana di fronte alla richiesta, proveniente dal tavolo nazionale, di ricandidare il deputato socialista uscente Riccardo Nencini. 
di tensione. In casi di contrasto insanabile, si è giunti, in sede regionale, alla defezione di una o l'altra delle componenti (i Verdi in Sicilia 1 e in Sardegna; Rifondazione comunista e la Rete in Basilicata; Psi e Rete in Sardegna, collegati in quei collegi alle candidature del Partito Sardo d'Azione) e solo in un caso ad una aperta rottura con conseguente presentazione di candidature alternative (in Sicilia, dove il Psi, una volta escluso da un tavolo negoziale egemonizzato dalla Rete, ha contrapposto candidature proprie a quelle del cartello dei «progressisti»).

Al termine di sofferte trattative, la ripartizione dei collegi fra le componenti del cartello progressista ha definito un quadro riportato, in un riepilogo per circoscrizione e per area geopolitica (il Nord senza l'Emilia Romagna, la «zona rossa», il Sud compreso il Lazio), nelle tabelle $3 a$ (Camera) e 3b, (Senato ${ }^{20}$. Come si può ricavare dai valori che vi sono riportati, si tratta di una ripartizione improntata a un criterio di tendenziale proporzionalizzazione dell'accordo. Ciascuna componente si è vista infatti attribuita una quota di collegi più o meno proporzionale alla sua forza elettorale presunta. In questa direzione convergevano molte delle modalità negoziali appena descritte, nonché lo stesso carattere nazionale dell'alleanza e la prevalenza, nel cartello progressista, di un personale politico e di apparati partitici da tempo sulla scena e legati quindi, per socializzazione e consuetudine, a metodi e logiche proporzionalistiche.

Il criterio della proporzionalizzazione si trova però, almeno in parte, relativizzato da tre ordini di motivi. In primo luogo

${ }^{20}$ Ricostruire la mappa dell'appartenenza partitica dei candidati di ciascuna aggregazione elettorale non è stata impresa semplice. Si tratta infatti di un'informazione non reperibile presso un'unica fonte (il Ministero degli interni non la possiede né vi sembra interessato; il Parlamento, nonostante la nuova disciplina della campagna elettorale abbia introdotto, per la Camera, una procedura che permette di riferire ciascun candidato a una sola formazione partitica anche quando sia espressione di un'aggregazione di forza - art. 9 della legge 515 del 10 dicembre 1993 -, ignora, almeno per il momento, la questione). Si è così fatto ricorso a dati e informazioni forniti dai partiti (Pds, Ad, Lega, Alleanza nazionale, Forza Italia, Ccd, Unione di Centro, Patto Segni, Partito Popolare), sottoposti a controllo incrociato e integrati per gli eletti, se necessario, dall'appartenenza ai gruppi parlamentari. Non sempre l'appartenenza partitica dei singoli candidati è stata però definibile con precisione, com'era del resto prevedibile in una fase di transizione partitica come quella in cui si sono svolte le elezioni di marzo. Alcuni candidati risultano espressi da più formazioni e sono quindi ad appartenenza plurima. Non sono mancati, in ciascuna aggregazione, $i$ tentativi di far passare per candidati altrui candidati propri o di proprio gradimento, per poterli così considerare come aggiuntivi rispetto alla propria quota ufficiale. Vi sono, infine, candidati non classificati, né a volte classificabili, in senso partitico. 
stimare il peso specifico di ciascuna componente costituiva impresa non facile. In una congiuntura politica fluida e a forte volatilità elettorale, i criteri cui riferirsi erano infatti aleatori. Le precedenti elezioni politiche apparivano remote e tutt'al più costituivano un possibile riferimento per le aree geografiche politicamente più stabili (tra queste, i collegi della «zona rossa»). Più affidabile poteva sembrare il riferimento alle elezioni amministrative del 1993, che consentiva di apprezzare alcune conseguenze del processo di destrutturazione partitica (per quanto riguarda lo schieramento progressita, ad esempio, la rilevanza ormai residuale del Psi). Quei risultati, in realtà, nascondevano più di un'insidia interpretativa e si erano prestati a letture distorte che avevano gonfiato non solo la consistenza della sinistra nel suo complesso, ma anche, al suo interno, la consistenza di componenti minori che avevano ben figurato nei ballottaggi quali Alleanza democratica o la Rete. In secondo luogo, il potere di ricatto e l'ostinazione negoziale dei partner minori, in particolare di quelli collocati alle frontiere dello schieramento, avevano introdotto nel negoziato un criterio di ponderazione aggiuntivo, ricaduto pressoché integralmente sulle spalle del Pds. Partito «più uguale degli altri» all'interno della coalizione e più impegnato dei suoi alleati (i quali peraltro gli hanno negato in ogni occasione la possibilità di esprimere un proprio esponente come candidato dei progressisti alla premiership di governo) al varo dell'alleanza progressista, il Pds si è così trovato a sacrificare in più occasioni le proprie posizioni per poter ricucire i ricorrenti strappi negoziali ${ }^{21}$. A causa di questa ponderazione, $i$ candidati in quota Pds sono ben al di sotto del $50 \%$ del totale - soglia che l'adozione di uno stretto criterio proporzionale sembrava poter suggerire -; e anche considerando come candidati per lo meno graditi al Pds buona parte di quelli «indipendenti», il livello non supera il $45 \%$ delle candidature complessive. Al Nord i candidati Pds sono meno che altrove (nel Veneto non raggiungono il $25 \%$ alla Camera e il $20 \%$ al Senato; in Piemonte il $37 \%$ del totale complessivo), ma anche al Sud sono al di sotto della media. Nella stessa zona rossa però, dove la ripartizione dei collegi si approssimava più che altrove a una distri-

${ }^{21}$ Le «rinunce» negoziali erano consapevolmente considerate dal vertice del Pds alla stregua di un rischio da correre, se il commento di uno dei suoi massimi dirigenti (Fabio Mussi), a trattative concluse, è stato: «se vinciamo ce n'è per tutti, se perdiamo perdiamo solo noi». 
TAB. 3a. Progressisti: appartenenza partitica dei candidati. Camera dei deputati

\begin{tabular}{|c|c|c|c|c|c|c|c|c|c|c|c|}
\hline circoscrizione & Pds & Rc & Rete & Verdi & Rs & Psi & Cs & Ad & Indip. & $\operatorname{Altri}\left({ }^{*}\right)$ & Tot. \\
\hline Piemonte 1 & 8 & 3 & 3 & 2 & & 1 & 1 & 1 & & & 19 \\
\hline Piemonte 2 & 5 & 3 & 1 & 1 & & 1 & 2 & 4 & & & 17 \\
\hline Lombardia 1 & 13 & 4 & 3 & 1 & & 5 & 1 & 3 & 1 & & 31 \\
\hline Lombardia 2 & 14 & 3 & 4 & 3 & & 3 & & 2 & 3 & & 32 \\
\hline Lombardia 3 & 3 & 1 & & & & 3 & & 2 & 2 & & 11 \\
\hline Trentino-Alto Adige & & & & 1 & & & 1 & & 1 & 4 & $\begin{array}{ll}7 & -1\end{array}$ \\
\hline Veneto 1 & 4 & 1 & 2 & 2 & & 2 & & 2 & 9 & & 22 \\
\hline Veneto 2 & 5 & 1 & 2 & 1 & & & 1 & & 5 & & 15 \\
\hline Friuli-Venezia Giulia & 2 & 3 & 1 & 2 & & & 1 & 1 & & & 10 \\
\hline Liguria & 3 & 3 & 2 & 1 & & 1 & 2 & 2 & & & 14 \\
\hline NORD & $\begin{array}{l}57 \\
32,0\end{array}$ & $\begin{array}{l}22 \\
12,4\end{array}$ & $\begin{array}{l}18 \\
10,1\end{array}$ & $\begin{array}{r}14 \\
7,9\end{array}$ & & $\begin{array}{l}16 \\
9,0\end{array}$ & $\begin{array}{l}9 \\
5,1\end{array}$ & $\begin{array}{l}17 \\
9,5\end{array}$ & $\begin{array}{l}21 \\
11,8\end{array}$ & $\begin{array}{l}4 \\
2,2\end{array}$ & $\begin{array}{l}178 \\
100,0\end{array}$ \\
\hline Emilia Romagna & 14 & 4 & & 3 & & 2 & 2 & 4 & & 3 & 32 \\
\hline Toscana & 19 & 3 & & 2 & & 3 & & 2 & & & 29 \\
\hline Umbria & 5 & 1 & & & & & & 1 & & & 7 \\
\hline Marche & 6 & 3 & & & & 2 & & 1 & & & 12 \\
\hline ZONA ROSSA $\begin{array}{l}\mathrm{N} \\
\%\end{array}$ & $\begin{array}{l}44 \\
55,0\end{array}$ & $\begin{array}{l}11 \\
13,75\end{array}$ & & $\begin{array}{l}5 \\
6,25\end{array}$ & & $\begin{array}{l}7 \\
8,75\end{array}$ & $\begin{array}{l}2 \\
2,5\end{array}$ & $\begin{array}{c}8 \\
10,0\end{array}$ & & $\begin{array}{l}3 \\
3,75\end{array}$ & $\begin{array}{l}80 \\
100,0\end{array}$ \\
\hline Lazio 1 & 12 & 2 & 3 & 6 & 1 & 1 & 2 & 4 & 1 & & 32 \\
\hline Lazio 2 & 5 & 1 & 2 & & & & 1 & 2 & & & 11 \\
\hline Abruzzi & 3 & 1 & & 1 & & 1 & & 1 & 3 & 1 & 11 \\
\hline Molise & 2 & & & & & & & 1 & & & 3 \\
\hline Campania 1 & 9 & 4 & 2 & 2 & & 3 & 1 & 3 & 1 & & 25 \\
\hline Campania 2 & 8 & 4 & & 1 & 1 & 3 & 2 & 2 & 1 & & 22 \\
\hline
\end{tabular}


TAB. 3a. (segue)

\begin{tabular}{|c|c|c|c|c|c|c|c|c|c|c|c|c|}
\hline circoscrizione & & Pds & $\mathrm{Rc}$ & Rete & Verdi & $\mathrm{Rs}$ & Psi & Cs & $\mathrm{Ad}$ & Indip. & $\operatorname{Altri}\left({ }^{\star}\right)$ & Tot. \\
\hline Puglia & & 16 & 4 & & 1 & & 4 & & 5 & 4 & & 34 \\
\hline Basilicata & & 1 & & & 1 & & 1 & & 1 & 1 & & 5 \\
\hline Calabria & & 5 & 2 & & 1 & & 2 & 1 & 2 & 4 & & 17 \\
\hline Sicilia 1 & & 6 & & 8 & & & & & & 4 & 2 & 20 \\
\hline Sicilia 2 & & 7 & 1 & 6 & & & & & 1 & 6 & & 21 \\
\hline Sardegna & & 7 & 5 & & & & & 2 & & & & 14 \\
\hline SUD & $\begin{array}{l}\mathrm{N} \\
\%\end{array}$ & $\begin{array}{l}81 \\
37,7\end{array}$ & $\begin{array}{l}24 \\
11,2\end{array}$ & $\begin{array}{l}21 \\
9,8\end{array}$ & $\begin{array}{l}13 \\
6,0\end{array}$ & $\begin{array}{l}2 \\
0,9\end{array}$ & $\begin{array}{c}15 \\
7,0\end{array}$ & $\begin{array}{l}9 \\
4,2\end{array}$ & $\begin{array}{l}22 \\
10,2\end{array}$ & $\begin{array}{l}25 \\
11,6\end{array}$ & $\begin{array}{l}3 \\
1,4\end{array}$ & $\begin{array}{l}215 \\
100,0\end{array}$ \\
\hline ITALIA & $\begin{array}{l}\mathrm{N} \\
\%\end{array}$ & $\begin{array}{c}182 \\
38,5\end{array}$ & $\begin{array}{l}57 \\
12,1\end{array}$ & $\begin{array}{c}39 \\
8,3\end{array}$ & $\begin{array}{l}32 \\
6,8\end{array}$ & $\begin{array}{l}2 \\
0,4\end{array}$ & $\begin{array}{l}38 \\
8,0\end{array}$ & 20 & $\begin{array}{l}47 \\
9,9\end{array}$ & $\begin{array}{l}46 \\
9,7\end{array}$ & $\begin{array}{l}10 \\
2,1\end{array}$ & $\begin{array}{l}473 \\
100,0\end{array}$ \\
\hline
\end{tabular}

(*) Per l'Alto Adige: candidature di centro-sinistra dell'Aggregazione Democratica Autonomista (Ada); per l'Emilia Romagna: «liste miste»; per gli Abruzzi: «cattolici»; per la Sicilia 1: «cattolici» e candidato non classificato.

Fonte: Elaborazione propria su dati forniti dalla Direzione del Pds e dal Comitato nazionale dei Progressisti. 
TAB. 3b. Progressisti: appartenenza partitica dei candidati. Senato della Repubblica

\begin{tabular}{|c|c|c|c|c|c|c|c|c|c|c|c|}
\hline circoscrizione & Pds & $\mathrm{Rc}$ & Rete & Verdi & Rs & Psi & Cs & $\mathrm{Ad}$ & Indip. & Altri $\left(^{\star}\right)$ & Tot. \\
\hline $\begin{array}{l}\text { Piemonte } \\
\text { Lombardia } \\
\text { Trentino-Alto Adige } \\
\text { Veneto } \\
\text { Friuli-Venezia Giulia } \\
\text { Liguria }\end{array}$ & $\begin{array}{r}7 \\
14 \\
2 \\
3 \\
1 \\
5\end{array}$ & $\begin{array}{l}2 \\
7 \\
3\end{array}$ & $\begin{array}{l}1 \\
1 \\
1 \\
1\end{array}$ & $\begin{array}{l}3 \\
1 \\
1\end{array}$ & & $\begin{array}{l}2 \\
4 \\
2 \\
2\end{array}$ & 1 & $\begin{array}{l}2 \\
2 \\
3 \\
1\end{array}$ & $\begin{array}{l}1 \\
4\end{array}$ & $\begin{array}{l}1 \\
3 \\
1\end{array}$ & $\begin{array}{r}17 \\
35 \\
6 \\
17 \\
5 \\
6\end{array}$ \\
\hline $\begin{array}{ll}\text { NORD } & \begin{array}{l}N \\
\%\end{array}\end{array}$ & $\begin{array}{l}32 \\
37,2\end{array}$ & $\begin{array}{l}12 \\
14,0\end{array}$ & $\begin{array}{l}4 \\
4,7\end{array}$ & $\begin{array}{l}5 \\
5,8\end{array}$ & & $\begin{array}{l}10 \\
11,6\end{array}$ & $\begin{array}{l}5 \\
5,8\end{array}$ & $\begin{array}{l}8 \\
9,3\end{array}$ & $\begin{array}{l}5 \\
5,8\end{array}$ & $\begin{array}{l}5 \\
5,8\end{array}$ & $\begin{array}{c}86 \\
100,0\end{array}$ \\
\hline $\begin{array}{l}\text { Emilia Romagna } \\
\text { Toscana } \\
\text { Umbria } \\
\text { Marche }\end{array}$ & $\begin{array}{l}7 \\
6 \\
1 \\
3\end{array}$ & $\begin{array}{l}1 \\
4 \\
1\end{array}$ & & $\begin{array}{l}1 \\
2\end{array}$ & & $\begin{array}{l}1 \\
1 \\
2 \\
1\end{array}$ & $\begin{array}{l}1 \\
1 \\
1\end{array}$ & $\begin{array}{l}3 \\
1\end{array}$ & & 2 & $\begin{array}{r}15 \\
14 \\
5 \\
6\end{array}$ \\
\hline ZONA ROSSA $\underset{\%}{N}$ & $\begin{array}{l}17 \\
42,5\end{array}$ & $\stackrel{6}{15,0}$ & & 3,5 & & $\stackrel{5}{12,5}$ & $\begin{array}{l}3 \\
7,5\end{array}$ & $\stackrel{4}{10,0}$ & & $\begin{array}{l}2 \\
5,0\end{array}$ & $\begin{array}{l}40 \\
100,0\end{array}$ \\
\hline $\begin{array}{l}\text { Lazio } \\
\text { Abruzzi } \\
\text { Molise } \\
\text { Campania } \\
\text { Puglia } \\
\text { Basilicata } \\
\text { Calabria } \\
\text { Sicilia } \\
\text { Sardegna }\end{array}$ & $\begin{array}{r}10 \\
3 \\
12 \\
7 \\
4 \\
2 \\
5 \\
3\end{array}$ & $\begin{array}{l}3 \\
1 \\
2 \\
2 \\
2 \\
3\end{array}$ & $\begin{array}{l}2 \\
1 \\
6\end{array}$ & $\begin{array}{l}2 \\
1\end{array}$ & 1 & $\begin{array}{l}2 \\
1 \\
1 \\
1 \\
1 \\
1 \\
1\end{array}$ & 2 & $\begin{array}{l}1 \\
1 \\
1 \\
1 \\
2\end{array}$ & $\begin{array}{l}1 \\
3 \\
3\end{array}$ & 1 & $\begin{array}{r}21 \\
5 \\
2 \\
22 \\
16 \\
5 \\
8 \\
20 \\
6\end{array}$ \\
\hline $\begin{array}{l}\mathrm{N} \\
\%\end{array}$ & $\begin{array}{l}46 \\
43,8\end{array}$ & $\begin{array}{l}13 \\
12,4\end{array}$ & $\begin{array}{l}10 \\
9,5\end{array}$ & $\begin{array}{l}6 \\
5,7\end{array}$ & $\begin{array}{l}1 \\
0,9\end{array}$ & $\begin{array}{l}8 \\
7,6\end{array}$ & $\begin{array}{l}5 \\
4,7\end{array}$ & $\begin{array}{l}8 \\
7,6\end{array}$ & $\begin{array}{l}7 \\
6,7\end{array}$ & $\begin{array}{l}1 \\
0,9\end{array}$ & $\begin{array}{l}105 \\
100,0\end{array}$ \\
\hline ITALIA & $\begin{array}{l}95 \\
41,1\end{array}$ & $\begin{array}{l}31 \\
13,4\end{array}$ & $\stackrel{14}{6,0}$ & $\begin{array}{c}14 \\
6,0\end{array}$ & $\begin{array}{l}1 \\
0,4\end{array}$ & $\begin{array}{l}23 \\
10,0\end{array}$ & ${ }^{13}, 6$ & 20 & 12 & $\begin{array}{l}8 \\
3,5\end{array}$ & $\begin{array}{l}231 \\
100,0\end{array}$ \\
\hline
\end{tabular}

(*) Per la Lombardia: candidato non classificato; per l'Alto Adige: candidature di centro-sinistra dell'Aggregazione Democratica Autonomista (Ada); per il Friuli-Venezia Giulia: candidatura Magnis; per l'Emilia Romagna: «liste miste»; per la Sicilia: «cattolici».

Fonte: Elaborazione propria su dati forniti dalla Direzione del Pds e dal Comitato nazionale dei Progressisti. 
buzione di spoglie reali, il Pds, pur facendo valere la sua supremazia territoriale, ha dovuto soddisfare le richieste degli alleati. Ad avvantaggiarsi dello «spirito di responsabilità» del partito della Quercia sono in particolare Rifondazione comunista e Alleanza democratica che nella zona rossa si aggiudicano, rispettivamente, il $15 \%$ e il $10 \%$ dei collegi, leggermente al di sopra della loro media. In Sicilia, invece, è la Rete a detenere una posizione predominante, coprendo un terzo dei collegi.

Per avvalorare l'ipotesi del «sacrificio» del Pds, e del correlativo vantaggio delle altre componenti dello schieramento, al criterio della distribuzione quantitativa dei collegi occorre affiancare il criterio della qualità degli stessi. È questo il terzo elemento che relativizza l'applicazione del criterio della proporzionalizzazione all'interno dello schieramento progressista. Una pur se indiretta misura della qualità dei collegi - indiretta poiché «esterna» e successiva alle logiche negoziali degli attori - è il rendimento elettorale delle candidature di ciascuna componente (Tab. 4). Se ne ricavano alcune significative conferme e qualche smentita. Rifondazione comunista esibisce il più elevato tasso di successo nello schieramento (pari a più del $45 \%$ tanto alla Camera quanto al Senato), superando il Pds che però, a fronte delle «rinunce» quantitative, è pur sempre riuscito a procurarsi collegi a tasso di successo piuttosto elevato (ovvero al di sopra del rendimento medio di schieramento). Un rendimento più basso caratterizza invece $\mathrm{i}$ candidati $\mathrm{di} \mathrm{Ad}$ - la cui presenza nel novero dei progressisti eletti nei collegi è inferiore alla sua incidenza sul totale dei candidati - e, soprattutto, quelli della Rete. Altri partner della coalizione - il Psi, il cui atteggiamento negoziale è stato, a ragion veduta, estremamente prudente, e i Verdi, maggiormente agguerriti - avevano puntato già nel corso della trattativa a massimizzare la qualità dei collegi più che il numero delle candidature e registrano così un rendimento piuttosto elevato.

Gli elementi e i dati fin qui considerati concorrono a definire il cartello elettorale progressista come un'alleanza dal profilo «difensivo», in cui l'esigenza delle singole componenti (in particolare dei partner minori del Pds) di ridurre i rischi competitivi e garantire le proprie posizioni prevale nei confronti dell'interesse generale dello schieramento, che avrebbe richiesto una maggiore capacità di proiezione esterna e di mobilitazione. $\mathrm{Ne}$ è risultato un assetto rigido, burocratizzato dal peso di apparati partitici che si sono impadroniti della trattativa con facilità ben 
TAB. 4. Progressisti: rendimento dei candidati nei collegi uninominali per appartenenza partitica

\begin{tabular}{|c|c|c|c|c|c|c|c|c|c|c|c|c|}
\hline & & $\mathrm{Pds}$ & $\mathrm{Rc}$ & Rete & Verdi & Rs & Psi & Cs & Ad & Indip. & Altri & Tot. \\
\hline \multicolumn{13}{|c|}{$\begin{array}{l}N^{\circ} \text { eletti alla } \\
\text { Camera dei deputati: }\end{array}$} \\
\hline $\begin{array}{l}\text { Nord } \\
\text { Zona rossa } \\
\text { Sud }\end{array}$ & & $\begin{array}{r}2 \\
43 \\
27\end{array}$ & $\begin{array}{r}5 \\
10 \\
11\end{array}$ & $\begin{array}{l}2 \\
- \\
4\end{array}$ & $\begin{array}{l}1 \\
5 \\
5\end{array}$ & $\overline{-}$ & $\begin{array}{l}2 \\
7 \\
5\end{array}$ & $\begin{array}{l}\overline{2} \\
3\end{array}$ & $\begin{array}{l}2 \\
7 \\
7\end{array}$ & $\overline{-}$ & $\begin{array}{l}- \\
3 \\
1\end{array}$ & $\begin{array}{l}14 \\
77 \\
73\end{array}$ \\
\hline Italia & $\begin{array}{l}\mathrm{N} \\
\%\end{array}$ & $\begin{array}{l}72 \\
39,5\end{array}$ & $\begin{array}{l}26 \\
45,6\end{array}$ & $\begin{array}{c}6 \\
15,4\end{array}$ & $\begin{array}{l}11 \\
34,4\end{array}$ & $\begin{array}{c}2 \\
100,0\end{array}$ & $\begin{array}{l}14 \\
36,8\end{array}$ & $\begin{array}{c}5 \\
25,0\end{array}$ & $\begin{array}{l}16 \\
34,0\end{array}$ & $\begin{array}{c}8 \\
17,4\end{array}$ & $\begin{array}{c}4 \\
40,0\end{array}$ & $\begin{array}{l}164 \\
34,7\end{array}$ \\
\hline \multicolumn{13}{|c|}{$\begin{array}{l}N^{\circ} \text { eletti al } \\
\text { Senato della Repubblica: }\end{array}$} \\
\hline $\begin{array}{l}\text { Nord } \\
\text { Zona rossa } \\
\text { Sud }\end{array}$ & & $\begin{array}{r}5 \\
17 \\
24\end{array}$ & $\begin{array}{l}1 \\
6 \\
7\end{array}$ & $\frac{-}{3}$ & $\begin{array}{l}1 \\
3 \\
3\end{array}$ & $\overline{-}$ & $\begin{array}{l}- \\
5 \\
5\end{array}$ & $\begin{array}{l}1 \\
3 \\
-\end{array}$ & $\begin{array}{l}1 \\
4 \\
2\end{array}$ & $\frac{-}{3}$ & $\begin{array}{l}1 \\
1 \\
-\end{array}$ & $\begin{array}{l}10 \\
39 \\
48\end{array}$ \\
\hline Italia & $\begin{array}{l}\mathrm{N} \\
\%\end{array}$ & $\begin{array}{l}46 \\
48,4\end{array}$ & $\begin{array}{l}14 \\
45,2\end{array}$ & $\begin{array}{c}3 \\
21,4\end{array}$ & $\begin{array}{c}7 \\
50,0\end{array}$ & $\begin{array}{c}1 \\
100,0\end{array}$ & $\begin{array}{l}10 \\
43,5\end{array}$ & $\begin{array}{c}4 \\
30,8\end{array}$ & $\begin{array}{c}7 \\
35,0\end{array}$ & $\begin{array}{l}3 \\
25,0\end{array}$ & $\begin{array}{c}2 \\
25,0\end{array}$ & $\begin{array}{l}97 \\
42,0\end{array}$ \\
\hline
\end{tabular}


maggiore di quanto non poterono fare nell'estate e nell'autunno 1993 al momento della selezione dei candidati alla carica di sindaco (processo discontinuo, poiché municipale, e relativo a cariche monocratiche e esecutive anziché rappresentative e quindi di più difficile cattura). Se ne ha conferma dalla prevalenza, in questa occasione, di «candidati-apparato» (anziché di «candidati-espressione della società civile») e dalla diffusa rinuncia a strategie «offensive» orientate a «spostare» voti mediante la presentazione dei candidati più forti in collegi deboli o incerti.

Lungo molte delle dimensioni esaminate, l'accordo di coalizione presenta, a destra, un profilo assai diverso, per certi rispetti speculare al precedente. La lunga e difficile gestazione dell'intesa, ad esempio, si salda con un fase negoziale che in tempi assai brevi giunge a definire l'accordo in tutti $i$ suoi aspetti. La rapidità del processo decisionale su aspetti politicamente delicati quali le decisioni di natura tecnico-elettorale incorporate all'accordo elettorale è stata favorita da molteplici condizioni. Anche nel caso dei due poli di destra, il numero degli attori si presentava piuttosto elevato (Tab. 2). La trattativa che doveva stabilire $\mathrm{i}$ termini dell'intesa è stata però condotta soltanto da due di essi - Forza Italia e la Lega nel Polo delle libertà; Forza Italia e Alleanza nazionale nel Polo del buongoverno -, poiché le altre componenti (il Ccd, l'Unione di Centro, l'esiguo Polo liberaldemocratico e i Riformatori di Pannella) erano rappresentate nel negoziato da Forza Italia, che ne ha assicurato le spettanze all'interno della sua quota. L'accordo è stato inoltre reso più facile dalle condizioni in cui $i$ tre partner principali sono pervenuti all'intesa. Berlusconi si trovava alla testa di una formazione nuova, senza passato politico, scevra quindi da ipoteche di apparati e di politici di professione e anzi alla ricerca di possibili candidati. La Lega e Alleanza nazionale, dal canto loro, potevano ragionevolmente contare su una prospettiva di crescita elettorale - e soprattutto, a seguito dell'accordo, di seggi parlamentari - e non avevano difficoltà a confermare (quasi tutti) gli «uscenti» senza scontentare gli «entranti». Un altro fattore che, a destra, ha reso più semplice la ripartizione dei collegi fra le componenti delle coalizioni è stato poi la centralizzazione del processo decisionale, condotto da un ristretto comitato di vertice. Mentre però nel Polo delle libertà l'accordo è senza falla - nonostante le resistenze manifestate localmente dalla Lega, soprattutto nei collegi attribuiti (da Berlusconi) a esponenti radicali -, il Polo del buon governo non sem- 
pre è riuscito a comporre i contrasti interni. È il caso di ben quattro circoscrizioni della Camera (Marche, Abruzzo, Molise e Campania 2) e di una circoscrizione del Senato (Abruzzo), in cui la destra è presente in ogni collegio con due candidati e pone così decisamente a repentaglio la propria competitività. Il dissidio ha contrapposto per lo più Alleanza nazionale al $\mathrm{Ccd}$, che, per radicamento proprio e per locale debolezza della formazione di Berlusconi, ne rappresentava il principale interlocutore. Il Ccd considerava le aree in questione, e in particolare l'Abruzzo e la Campania, proprie zone di influenza, reclamandovi un congruo numero di collegi. Alleanza nazionale nutriva ambizioni analoghe, puntando a far valere nella trattativa i successi ottenuti in quelle aree nel voto amministrativo dell'autunno $1993^{22}$. L'indisponibilità del Ccd a recedere, la studiata arrendevolezza del vertice missino alle insistenze delle proprie istanze locali - le quali confidavano nella possibilità di conquistare alcuni seggi parlamentari anche con le sole proprie forze e manifestavano forti riserve su alcuni dei candidati proposti dai cristiano-democratici (ritenuti «impresentabili» in quanto espressione del vecchio personale politico ex democristiano) -, l'entità della posta in gioco (la fedeltà dei clienti di Gaspari in Abruzzo e la posizione di Mastella in Campania), la latitante equidistanza di Forza Italia fra le parti: tutto ciò ha reso la rottura inevitabile.

Anziché al criterio della proporzionalizzazione, l'accordo si è ispirato, a destra, a una distribuzione compensativa dei collegi. La ripartizione dei collegi è infatti avvenuta sulla base di quote che concedono molto alla Lega (al Nord) e a Alleanza nazionale (al Sud) e compensano in tal modo il vantaggio politico che Forza Italia - l'attore aggregante presente in entrambe le combinazioni - trae dalla doppia alleanza e dalla possibilità di sviluppare strategie di coalizione negate ai suoi partner. La distribuzione compensativa presenta grandezze diverse nei due casi in esame. I valori riportati nelle tabelle 5a (Camera) e 5b (Senato), ad esempio, indicano che la Lega si aggiudica i due terzi dei 347 collegi uninominali di Camera e Senato in cui è presente un candidato del Polo delle libertà. Più specificamente, tale percentuale supera il $70 \%$ dei collegi lombardi. Se si passa al Polo del buon governo (tabb. 6a e 6b), la ripartizione dei colle-

\footnotetext{
${ }^{22}$ In particolare la destra aveva conquistato il municipio di Benevento dopo un ballottaggio che l'aveva contrapposta proprio a un esponente della corrente di Mastella.
} 
TAB. 5a. Polo delle libertà: appartenenza partitica dei candidati. Camera dei deputati

\begin{tabular}{|c|c|c|c|c|c|c|c|c|}
\hline circoscrizione & Lega & Forza Italia & Ccd & Udc & Riformatori & Pld & Tot. & \\
\hline Piemonte 1 & 11 & 6 & 2 & & & & 19 & \\
\hline Piemonte 2 & 12 & 4 & & 1 & & & 17 & \\
\hline Lombardia 1 & 18 & 9 & & & 2 & 2 & 31 & \\
\hline Lombardia 2 & 26 & 4 & 1 & & 1 & & 32 & \\
\hline Lombardia 3 & 6 & 4 & & & 1 & & 11 & \\
\hline Trentino-Alto Adige & 4 & 2 & & & & & 6 & -2 \\
\hline Veneto 1 & 14 & 3 & 3 & & 2 & & 22 & \\
\hline Veneto 2 & 9 & 4 & 2 & & & & 15 & \\
\hline Friuli-Venezia Giulia & 7 & 3 & & & & & 10 & \\
\hline Liguria & 9 & 3 & & 2 & & & 14 & \\
\hline NORD & $\begin{array}{l}116 \\
65,6\end{array}$ & $\begin{array}{l}42 \\
23,7\end{array}$ & $\begin{array}{l}8 \\
4,5\end{array}$ & $\begin{array}{l}3 \\
1,7\end{array}$ & $\begin{array}{l}6 \\
3,4\end{array}$ & $\begin{array}{l}2 \\
1,1\end{array}$ & $\begin{array}{l}177 \\
100,0\end{array}$ & \\
\hline Emilia Romagna & 18 & 10 & 3 & & & & 31 & -1 \\
\hline Toscana & 15 & 8 & 4 & & & & 27 & -2 \\
\hline ZONA ROSSA $\underset{\%}{\mathrm{~N}}$ & $\begin{array}{l}33 \\
56,9\end{array}$ & $\begin{array}{l}18 \\
31,0\end{array}$ & $\begin{array}{c}7 \\
12,1\end{array}$ & & & & $\begin{array}{c}58 \\
100,0\end{array}$ & \\
\hline Totale & $\begin{array}{l}149 \\
63,4\end{array}$ & $\begin{array}{l}60 \\
25,5\end{array}$ & $\begin{array}{l}15 \\
6,4\end{array}$ & $\begin{array}{l}3 \\
1,3\end{array}$ & $\begin{array}{l}6 \\
2,6\end{array}$ & $\begin{array}{l}2 \\
0,8\end{array}$ & $\begin{array}{l}235 \\
100,0\end{array}$ & \\
\hline
\end{tabular}

Fonte: Elaborazione propria su dati forniti dalla Segreteria organizzativa della Lega Nord, dall'Ufficio coordinamento territoriale di Forza Italia e dal Coordinamento nazionale del Centro Cristiano Democratico. 
TAB. 5b. Polo delle libertà: appartenenza partitica dei candidati. Senato della repubblica

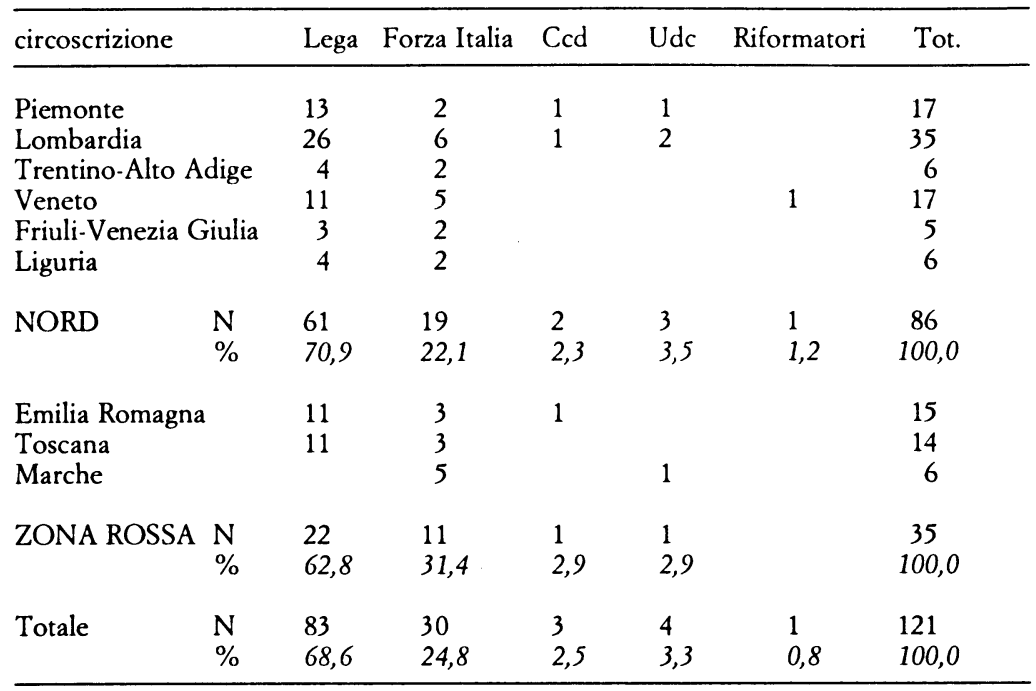

Fonte: Elaborazione propria su dati forniti dalla Segreteria organizzativa della Lega Nord, dall'Ufficio coordinamento territoriale di Forza Italia e dal Coordinamento nazionale del Centro Cristiano Democratico.

gi risulta invece grosso modo paritetica, pur se leggermente sbilanciata a favore di Alleanza nazionale che si vede riconosciuta una posizione di preminenza in alcune aree di più solido radicamento missino (è il caso, ad esempio, della Puglia - in cui $\mathrm{Al}$ leanza nazionale si aggiudica il $74 \%$ del totale dei collegi, pari al $82,3 \%$ dei collegi della Camera - e, in proporzioni minori, di Basilicata e Campania).

Questa differenziata declinazione del modello deve ricollegarsi ai diversi binari su cui corre lo scambio negoziale nelle due aggregazioni di destra e, in particolare al diverso costo che l'operazioni riveste per Forza Italia. Nei confronti della Lega, Forza Italia si trova infatti a dover concedere molto poiché deve assicurarsi un alleato riottoso e corteggiato anche da altri (Segni in primo luogo), cui deve, per di più, far accettare un assetto coalizionale complessivo poco gradito (ovvero l'alleanza, per quanto indiretta e implicita, con Alleanza nazionale). La Lega, lo si è già detto, sceglie Berlusconi proprio per le migliori condizioni che quest'ultimo è in grado di assicurarle, nonché per alcune convenienze aggiuntive - alcune delle quali sarebbero risultate in parte illusorie - relative al carattere meno vinco- 
lante di un'intesa confinata al momento elettorale, a una presunzione di superiorità sul «terreno» (rispetto a una formazione come Forza Italia, a quel momento ancora «virtuale» e evidentemente priva di un proprio radicamento periferico), alla possibile copertura informativa che Berlusconi avrebbe potuto assicurare alla Lega.

Rispetto a Alleanza nazionale, la posizione negoziale di Forza Italia è più solida e il costo dell'accordo, di conseguenza, meno gravoso. Alleanza nazionale è infatti attore politico marginale e isolato che solo grazie a Forza Italia riesce a inserirsi nel gioco delle alleanze. Per Fini, l'alleanza con Berlusconi riveste quindi di per sé un valore strategico di fondo, di natura legittimante. Costituisce pertanto un primo risultato assai apprezzabile, che si arricchisce di un prezioso corollario: la possibilità di accreditarsi, nel confronto a distanza con la Lega, come il partner più responsabile e il vero interlocutore politico di Berlusconi. E tutto ciò, evidentemente, facilita l'accordo sulla ripartizione dei collegi, laddove accordo c'è.

TAB. 6a. Polo del buon governo: appartenenza partitica dei candidati. Camera dei deputati

\begin{tabular}{|c|c|c|c|c|c|c|c|c|}
\hline circoscrizione & & An & Forza Italia & Ccd & Udc & Altri $\left({ }^{\star}\right)$ & Tot. & \\
\hline Umbria & & 3 & 2 & 1 & & 1 & 7 & \\
\hline Lazio 1 & & 13 & 10 & 7 & 1 & & 31 & -1 \\
\hline Lazio 2 & & 5 & 5 & 1 & & & 11 & \\
\hline Campania 1 & & 13 & 9 & 3 & & & 25 & \\
\hline Puglia & & 28 & 5 & & & 1 & 34 & \\
\hline Basilicata & & 3 & 1 & 1 & & & 5 & \\
\hline Calabria & & 9 & 5 & 2 & 1 & & 17 & \\
\hline Sicilia 1 & & 8 & 10 & 2 & & & 20 & \\
\hline Sicilia 2 & & 13 & 5 & 2 & 1 & & 21 & \\
\hline Sardegna & & 4 & 8 & 2 & & & 14 & \\
\hline SUD & $\begin{array}{l}\mathrm{N} \\
\%\end{array}$ & $\begin{array}{l}96 \\
53,9\end{array}$ & $\begin{array}{l}58 \\
32,6\end{array}$ & $\begin{array}{l}20 \\
11,2\end{array}$ & $\begin{array}{l}3 \\
1,7\end{array}$ & $\begin{array}{l}1 \\
0,6\end{array}$ & $\begin{array}{l}178 \\
100,0\end{array}$ & \\
\hline Totale & $\begin{array}{l}\mathrm{N} \\
\%\end{array}$ & $\begin{array}{l}99 \\
53,5\end{array}$ & $\begin{array}{l}60 \\
32,4\end{array}$ & $\begin{array}{l}21 \\
11,4\end{array}$ & $\begin{array}{l}3 \\
1,6\end{array}$ & $\begin{array}{l}2 \\
1,1\end{array}$ & $\begin{array}{l}185 \\
100,0\end{array}$ & \\
\hline
\end{tabular}

(*) Per l'Umbria: candidatura della formazione civica «Uniti per l'Umbria»; per la Puglia: candidatura indipendente di centro-destra.

Fonte: Elaborazione propria su dati forniti dal Settore elettorale del Msi-Alleanza nazionale, dall'Ufficio coordinamento territoriale di Forza Italia e dal Coordinamento nazionale del Centro Cristiano Democratico. 
TAB. 6b. Polo del buon governo: appartenenza partitica dei candidati. Senato della Repubblica

\begin{tabular}{|c|c|c|c|c|c|c|}
\hline circoscrizione & An & Forza Italia & $\mathrm{Ccd}$ & Udc & Tot. & \\
\hline Lazio & 13 & 5 & 3 & & 21 & \\
\hline Molise & 1 & 1 & & & 2 & \\
\hline Campania & 12 & 3 & 7 & & 22 & \\
\hline Puglia & 9 & 4 & 3 & & 16 & \\
\hline Basilicata & 3 & 1 & 1 & & 5 & \\
\hline Calabria & 3 & 4 & 1 & & 8 & \\
\hline Sicilia & 10 & 7 & 2 & 1 & 20 & \\
\hline Sardegna & 1 & 3 & & 1 & 5 & -1 \\
\hline SUD & $\begin{array}{l}52 \\
52,5\end{array}$ & $\begin{array}{l}28 \\
28,3\end{array}$ & $\begin{array}{l}17 \\
17,2\end{array}$ & $\begin{array}{l}2 \\
2,0\end{array}$ & $\begin{array}{c}99 \\
100,0\end{array}$ & \\
\hline
\end{tabular}

Fonte: Elaborazione propria su dati forniti dal Settore elettorale del Msi-Alleanza nazionale, dall'Ufficio coordinamento territoriale di Forza Italia e dal Coordinamento nazionale del Centro Cristiano Democratico.

In entrambe le aggregazioni, tuttavia, Forza Italia paga un costo aggiuntivo connesso al rendimento dei propri candidati nei collegi, sensibilmente inferiore, come si può osservare nelle tabelle $7 \mathrm{a}$ (Polo delle libertà) e $7 \mathrm{~b}$ (Polo del buon governo), al rendimento dei candidati della Lega e di Alleanza nazionale. Sia che tale costo fosse incorporato all'accordo - e quindi dovuto alla consapevole concessione dei collegi ritenuti più sicuri ai propri alleati -, sia che si sia trattato invece di un costo imprevisto e soltanto «successivo» - e quindi imputabile a inesperienza politica e/o a imperizia negoziale - ciò rende il modello della distribuzione compensativa ancor più squilibrato.

Una volta definite, nelle trattative bilaterali, le quote fra le parti, alcuni collegi in quota Forza Italia vengono attribuiti ai partner minori dell'alleanza. Il dettaglio di tale ripartizione (riportato nelle tabb. 5 e 6) evidenzia la diversa consistenza di tali componenti e, in particolare, il maggior peso del Ccd - componente più strutturata e radicata fra quelle minori, che darà vita in Parlamento a un gruppo autonomo anziché confluire in Forza Italia - che esibisce, soprattutto nel Polo del buon governo (di cui esprime il $13 \%$ dei 284 candidati complessivi), una presenza da forza intermedia. Anche a giudicare dal rendimento delle candidature relative (si vedano le Tabb. 7 a e $7 \mathrm{~b}$ ), si tratta per lo più di spoglie reali, ovvero di collegi sicuri, cortesemente octroyées da Forza Italia a segmenti di classe politica «uscente» 
TAB. 7a. Polo delle libertà: rendimento dei candidati nei collegi uninominali del Nord (Emilia Romagna esclusa) per appartenenza partitica $\left(^{*}\right)$

\begin{tabular}{|c|c|c|c|c|c|c|c|c|}
\hline & & Lega & Forza Italia & Ccd & Udc & Riformatori & Pld & Tot. \\
\hline \multicolumn{9}{|c|}{ Camera dei deputati: } \\
\hline Nord & $\begin{array}{l}\text { N eletti } \\
\%\end{array}$ & $\begin{array}{l}106 \\
91,4\end{array}$ & $\begin{array}{l}36 \\
85,7\end{array}$ & $\begin{array}{c}8 \\
100,0\end{array}$ & $\stackrel{3}{100,0}$ & $\begin{array}{c}6 \\
100,0\end{array}$ & $\stackrel{2}{100,0}$ & $\begin{array}{c}161 \\
90,9\end{array}$ \\
\hline \multicolumn{9}{|c|}{ Senato della Repubblica: } \\
\hline Nord & $\begin{array}{l}N \text { eletti } \\
\%\end{array}$ & $\begin{array}{l}54 \\
88,5\end{array}$ & $\begin{array}{l}13 \\
68,4\end{array}$ & $\begin{array}{c}2 \\
100,0\end{array}$ & $\begin{array}{c}3 \\
100,0\end{array}$ & $\begin{array}{c}1 \\
100,0\end{array}$ & - & $\begin{array}{l}73 \\
84,9\end{array}$ \\
\hline
\end{tabular}

(*) Il Polo delle libertà ha eletto in Emilia Romagna tre candidati alla Camera (due di Forza Italia e uno della Lega) e uno al Senato (leghista).

TAB. 7b. Polo del buon governo: rendimento dei candidati nei collegi uninominali del Sud (Lazio incluso) per appartenenza partitica

\begin{tabular}{|c|c|c|c|c|c|c|}
\hline & & An & Forza Italia & $\mathrm{Ccd}$ & Udc & Tot. \\
\hline \multicolumn{7}{|c|}{ Camera dei deputati: } \\
\hline Sud & $\begin{array}{l}\mathrm{N} \text { eletti } \\
\%\end{array}$ & $\begin{array}{l}77 \\
80,2\end{array}$ & $\begin{array}{l}34 \\
58,6\end{array}$ & $\begin{array}{l}13 \\
65,0\end{array}$ & $\begin{array}{c}3 \\
100,0\end{array}$ & $\begin{array}{l}127 \\
71,3\end{array}$ \\
\hline \multicolumn{7}{|c|}{ Senato della Repubblica: } \\
\hline Sud & $\begin{array}{l}\mathrm{N} \text { eletti } \\
\%\end{array}$ & $\begin{array}{l}34 \\
65,4\end{array}$ & $\begin{array}{l}10 \\
35,7\end{array}$ & $\begin{array}{c}8 \\
58,8\end{array}$ & $\stackrel{2}{100,0}$ & $\begin{array}{l}54 \\
54,5\end{array}$ \\
\hline
\end{tabular}

che avevano accolto favorevolmente l'ingresso di Berlusconi nell'arena elettorale e ne avevano sostenuto il disegno nella fase di formazione delle alleanze. Come si può ricavare dalle tabelle 5 e 6, l'attribuzione dei collegi ai partner minori dell'alleanza segue il criterio del radicamento territoriale personale e di componente - si osservi la distribuzione dei centristi liberali e la concentrazione dei candidati cristiano-democratici nel Veneto, nel Lazio e in Campania -, il che costituisce, in alcuni casi, un fattore di rafforzamento «esterno» dell'alleanza ${ }^{23}$.

${ }^{23}$ Il leader dell'Unione di Centro Raffaele Costa, ad esempio, risulta eletto con una percentuale di voti validi fra le più alte (il $66,2 \%$ ) e con il distacco più consistente nei confronti del secondo $(+49,4$ punti percentuali). 
Le modalità dell'intesa e i rapporti fra i partner coalizionali evidenziano la diversificazione territoriale e politica, e quindi la flessibilità, come i tratti salienti del duplice accordo elettorale che si realizza a destra. Si tratta di caratteristiche che ben si adattano alle nuove regole di voto, ma che favoriscano anche il prodursi di due vistosi limiti competitivi: l'intersecarsi dei poli nei collegi del Nord e le situazioni a polo diviso in alcune circoscrizioni del Sud. Nei collegi del Nord, le destre sono infatti presenti oltre che con le candidature del Polo delle libertà anche con quelle di Alleanza nazionale, la cui leadership lascia cadere l'ipotesi delle desistenze concordate, avanzata da Berlusconi, per non apparire arrendevole di fronte all'ostilità della Lega e non rinunciare all'ambizione di essere forza politica di impianto nazionale ${ }^{24}$. Meno gravosa in termini elettorali, ma ben più gratuita in termini politici, risulta invece la divisione del Polo del buon governo di cui si è già detto $\mathrm{O}^{25}$.

Al di là di questi limiti competitivi, l'accordo, com'era già desumibile dalle modalità negoziali che l'avevano preceduto, appare fortemente orientato alla proiezione esterna dello schieramento e al risultato (anziché rimanere invischiato in tensioni e conflitti interni come nel caso del Polo progressita). È essenzialmente questo tipo di assetto, che non riesce a occultare la scarsa coerenza fra i diversi «pezzi» dell'alleanza, a costituire la invenzione di Berlusconi, il quale in questa strategia coalizionale trasferisce criteri e modalità mutuati dalle strategie commerciali adottate dal suo gruppo imprenditoriale ${ }^{26}$.

24 In caso di desistenza e nell'ipotesi, forse un po' temeraria dal punto di vista politico, di un «trasferimento» dei voti andati ai candidati di Alleanza nazionale a favore dei candidati del Polo delle libertà, quest'ultimo avrebbe ottenuto 11 seggi in più alla Camera (pari al 2,3\% dei seggi uninominali) e 11 al Senato (pari al 4,7\% dei seggi uninominali), andati a candidati del polo progressista.

25 Il polo «diviso» costa al Polo del buon governo 30 seggi alla Camera (pari al $6,3 \%$ dei seggi uninominali) e 5 al Senato (pari al $2,1 \%$ dei seggi uninominali), andati a candidati progressisti e in tre casi, per la Camera, a candidati del centro.

${ }_{26}$ Dal modello della distribuzione compensativa al rapporto instaurato con $i$ partner all'interno dei due schieramenti, le analogie non mancano. Forza Italia punta ad esempio, come la Fininvest, alla «diversificazione del prodotto» e costruisce il rapporto con gli alleati secondo assetti che ricordano da vicino il modello dell'impresa rete a più centri di gravità (Butera 1991, 51-100). Un breve ma efficace profilo dell'attività imprenditoriale del leader di Forza Italia, che ben si adatta anche alle modalità del suo ingresso in politica, è stato redatto in occasione del conferimento a Berlusconi di una laurea honoris causa in ingegneria gestionale presso l'Università della Calabria (Del Monte 1991). 
Intermedio rispetto ai due precedenti si presenta, per molti aspetti, il caso della coalizione centrista. Nonostante il ridotto numero di attori rilevanti (sostanzialmente due: Segni da un lato, il Ppi dall'altro), l'aggregazione di centro ha vissuto, ad esempio, una fase negoziale piuttosto travagliata, soprattutto a causa del disaccordo sui criteri di selezione dei candidati, in margine al quale $\mathrm{i}$ partner sono giunti al limite della rottura ${ }^{27}$. La diversa configurazione dei due attori - uno dei quali, il Ppi, a strutturazione periferica non ovunque salda ma comunque ben definita e articolata, l'altro, il Patto Segni, dotato localmente soltanto di alcuni gracili osservatòri regionali - ha inoltre reso ibrido il livello negoziale. Le trattative si sono infatti svolte su base regionale, ma sono state condotte al centro, con la partecipazione dei coordinatori regionali delle due parti, affiancati da esponenti nazionali, ai quali, soprattutto nel caso del Patto Segni, era affidata l'ultima parola.

Una volta risolta la controversia sui criteri da adottare per la scelta dei candidati, le due componenti del Patto per l'Italia raggiungono senza ulteriori difficoltà l'accordo sulla distribuzione dei collegi. L'impossibilità di contare su collegi davvero «sicuri» e i diversi rapporti di forza politico-organizzativa fra le parti hanno facilitato il raggiungimento dell'intesa. La prima condizione sdrammatizzava la «corsa al collegio» (drammatizzando semmai in alcuni collegi la «corsa al candidato») e rendeva l'attribuzione dei collegi alle singole componenti appetibile soprattutto nel caso dei collegi senatoriali, poiché ne sarebbe direttamente dipesa la ripartizione dei seggi proporzionali eventualmente conseguiti dall'aggregazione centrista. La seconda condizione forniva, a sua volta, un criterio di riferimento oggettivo per definire, caso regionale per caso regionale, le rispettive quote.

Le tabelle $8 \mathrm{a}$ (Camera) e $8 \mathrm{~b}$ (Senato) riportano l'articolazione complessiva delle candidature del Patto per l'Italia. Se ne ricava anzitutto il peso complessivo delle singole componenti. Il

${ }^{27}$ Il Patto Segni, favorevole a un profondo rinnovamento delle candidature e contrario quindi alla riproposizione degli esponenti della vecchia guardia Dc (fossero coinvolti o non in inchieste giudiziarie), si è scontrato a riguardo con le posizioni assai meno drastiche dei popolari. Le parti hanno trovato un'intesa affidando a Segni una sorta di giudizio ultimativo sulle candidature nei collegi uninominali e riservandosi piena autonomia rispetto alla formazione delle proprie liste per il voto proporzionale della Camera. 
TAB. 8a. Patto per l'Italia: appartenenza partitica dei candidati. Camera dei deputati

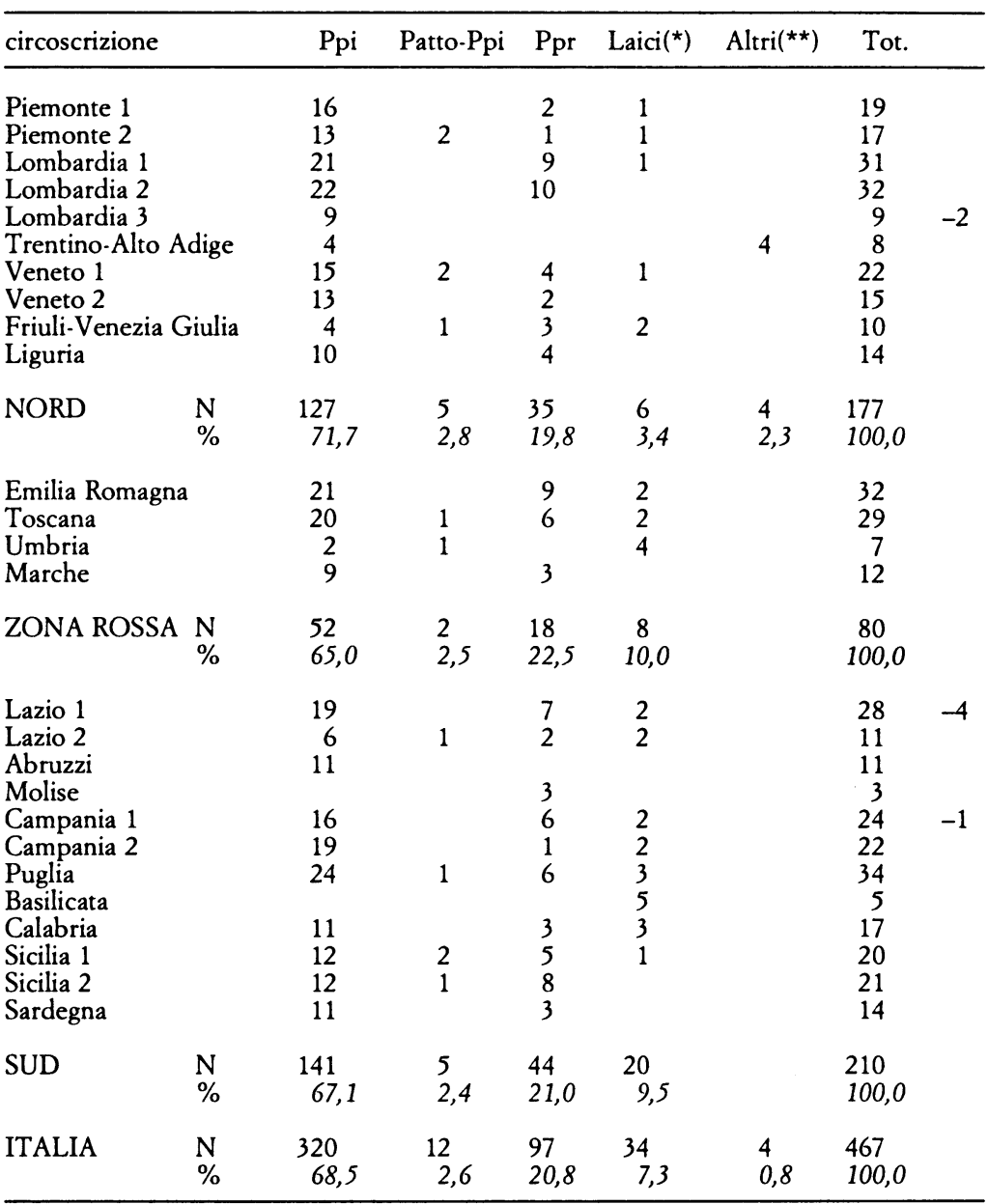

(*) Si tratta di 17 socialisti (Lombardia 1: 1; Veneto 1: 1; Friuli-Venezia Giulia: 1; Umbria: 2; Campania 1: 1; Campania 2: 2; Puglia: 1; Basilicata: 5 candidati di Autonomia socialista; Calabria: 3 candidati del Movimento liberal-socialista), di nove repubblicani (Friuli-Venezia Giulia: 1; Emilia Romagna: 2; Toscana: 2; Umbria: 2; Lazio 2: 1; Puglia: 1), di sei liberali (Piemonte 1: 1; Piemonte 2: 1; Lazio1: 1; Campania1: 1; Puglia: 1; Sicilia 1: 1), di due socialdemocratici (Lazio 1 e Lazio 2).

(**) Si tratta delle candidature di centro-sinistra dell'Aggregazione Democratica Autonomista (Ada).

Fonte: Elaborazione propria su dati forniti dall'Ufficio organizzazione del Partito popolare e dai Popolari per la Riforma (Ufficio centrale e responsabili regionali di Trentino, Lombardia, Toscana). 
TAB. 8b. Patto per l'Italia: appartenenza partitica dei candidati. Senato della Repubblica

\begin{tabular}{|c|c|c|c|c|c|c|c|}
\hline \multicolumn{2}{|l|}{ circoscrizione } & Ppi & Patto-Ppi & Ppr & Laici $\left(^{\star}\right)$ & Altri $(* *)$ & Tot. \\
\hline \multicolumn{2}{|l|}{ Piemonte } & 11 & & & 6 & & 17 \\
\hline \multicolumn{2}{|l|}{ Lombardia } & 23 & 2 & 8 & & 2 & 35 \\
\hline \multicolumn{2}{|c|}{ Trentino-Alto Adige } & 2 & & & 1 & 3 & 6 \\
\hline \multicolumn{2}{|l|}{ Veneto } & 15 & & 1 & 1 & & 17 \\
\hline \multicolumn{2}{|c|}{ Friuli-Venezia Giulia } & 2 & & 2 & & 1 & 5 \\
\hline \multicolumn{2}{|c|}{ Liguria } & 5 & & 1 & & & 6 \\
\hline \multirow[t]{2}{*}{ NORD } & $\mathrm{N}$ & 58 & 2 & 12 & 8 & 6 & 86 \\
\hline & $\%$ & 67,4 & 2,3 & 14,0 & 9,3 & 7,0 & 100,0 \\
\hline \multicolumn{2}{|c|}{ Emilia Romagna } & 8 & & 4 & 3 & & 15 \\
\hline \multicolumn{2}{|l|}{ Toscana } & 7 & 1 & 4 & 1 & 1 & 14 \\
\hline \multicolumn{2}{|l|}{ Umbria } & 3 & & & 2 & & 5 \\
\hline \multicolumn{2}{|l|}{ Marche } & 3 & 1 & 1 & 1 & & 6 \\
\hline \multirow[t]{2}{*}{ ZONA ROSSA } & $\mathrm{N}$ & 21 & 2 & 9 & 7 & 1 & 40 \\
\hline & $\%$ & 52,5 & 5,0 & 22,5 & 17,5 & 2,5 & 100,0 \\
\hline \multirow{2}{*}{\multicolumn{2}{|c|}{$\begin{array}{l}\text { Lazio } \\
\text { Abruzzi }\end{array}$}} & 14 & & 2 & 5 & & 21 \\
\hline & & 5 & & & & & 5 \\
\hline \multicolumn{2}{|l|}{ Molise } & 2 & & & & & 2 \\
\hline \multicolumn{2}{|l|}{ Campania } & 15 & 2 & 3 & 2 & & 22 \\
\hline \multicolumn{2}{|l|}{ Puglia } & 13 & & 1 & 2 & & 16 \\
\hline \multicolumn{2}{|l|}{ Basilicata } & 5 & & & & & 5 \\
\hline \multicolumn{2}{|l|}{ Calabria } & 6 & & 2 & & & 8 \\
\hline \multirow{2}{*}{\multicolumn{2}{|c|}{$\begin{array}{l}\text { Sicilia } \\
\text { Sardegna }\end{array}$}} & 12 & & 8 & & & 20 \\
\hline & & 5 & 1 & & & & 6 \\
\hline \multirow[t]{2}{*}{ SUD } & $\mathrm{N}$ & 77 & 3 & 16 & 9 & & 105 \\
\hline & $\%$ & 73,3 & 2,9 & 15,2 & 8,6 & & 100,0 \\
\hline \multirow[t]{2}{*}{ ITALIA } & $\mathrm{N}$ & 156 & 7 & 37 & 24 & 7 & 231 \\
\hline & $\%$ & 67,5 & 3,05 & 16,0 & 10,4 & 3,05 & 100,0 \\
\hline
\end{tabular}

$\left.{ }^{*}\right)$ Si tratta di quattro socialisti (Emilia Romagna: 1; Lazio: 2; Campania: 1), di 10 repubblicani (Piemonte: 2; Veneto: 1; Emilia Romagna: 2; Toscana: 1; Umbria: 1; Marche: 1; Lazio: 1; Puglia: 1), di sei liberali (Piemonte: 4; Campania: 1; Puglia: 1), di tre socialdemocratici (Trentino-Alto Adige, Umbria, Lazio), di un candidato di orientamento socialista-repubblicano (Lazio).

$\left.{ }^{\star \star \star}\right)$ Si tratta di due candidati non classificati (Lombardia), delle candidature di centro-sinistra dell'Aggregazione Democratica Autonomista (Ada) (Trentino-Alto Adige), di una candidatura indipendente (Toscana).

Fonte: Elaborazione propria su dati forniti dall'Ufficio organizzazione del Partito popolare e dai Popolari per la Riforma (Ufficio centrale e responsabili regionali di Trentino, Lombardia, Toscana). 
Partito popolare si aggiudica grosso modo il $70 \%$ dei collegi (attribuendo in quota Ppi metà delle candidature indicate nelle tabelle come candidature comuni Ppi-Patto), facendo valere per intero, nel corso della trattativa, una capacità politico-organizzativa evidentemente di gran lunga maggiore a quella di un partner non ancora ben strutturato (i Popolari per la riforma) o ridotto a pura aggregazione di personalità (i laici alleati di Segni). Anche per questo motivo, il dato medio nazionale nasconde differenze regionali a volte accentuate. Il peso dei popolari nell'alleanza di centro è al di sopra della media nazionale in alcune importanti regioni del Sud - la Puglia e la Campania - e in quasi tutte le regioni del Nord - più nel Veneto, dove i pattisti subiscono le rudezze negoziali della coordinatrice dei popolari Rosy Bindi e il rapporto tra le due componenti è di 80 contro 20, che non in Lombardia, dove i pattisti traggono qualche vantaggio dalla simpateticità con Roberto Formigoni, coordinatore dei popolari lombardi. I pattisti di Segni si aggiudicano invece un maggior numero di collegi nelle regioni della zona rossa, in cui detengono fra il $40 \%$ e il $50 \%$ delle candidature del Patto per l'Italia, come pure in Sicilia. Un terzo elemento relativo all'appartenenza partitica dei candidati centristi è il peso dei laici all'interno del Patto Segni. Le tabelle 8a e 8b presentano in dettaglio il peso specifico di ciascuna componente. Ne emerge una distribuzione che riproduce, su scala minore e in via residuale, alcune caratteristiche della situazione precedente la destrutturazione dei partiti tradizionali: la concentrazione dei candidati liberali nei collegi piemontesi e campani; la presenza di esponenti socialisti - capeggiata in un paio di occasioni da parlamentari uscenti collegati per il riparto proporzionale a liste self made («fai-da-te») - nei collegi del Sud (Campania, Calabria, Basilicata); l'attribuzione di alcuni collegi della zona rossa, in particolare dell'Emilia Romagna, ai repubblicani.

Riassumendo, l'analisi delle alleanze e del tipo di accordi che le hanno sostenute segnala il numero degli attori (rilevanti) coinvolti nel processo negoziale, il grado di concentrazione/dispersione del negoziato (sedi e processi decisionali) e la stessa estensione territoriale dell'accordo come i fattori che maggiormente influenzano il come di ciascuna aggregazione. Tali modalità incidono infatti tanto sul grado di conflittualità negoziale e sui tempi del processo decisionale, quanto, come ha mostrato l'analisi, sullo stesso criterio regolativo di massima che governa l'accordo fra le componenti di ciascun polo (la proporzionaliz- 
zazione a sinistra, la distribuzione compensativa a destra, il peso della strutturazione dei partner e dei rapporti di forza regionali al centro) (Tab. 9). Le differenze che l'analisi ha consentito di fermare - differenze le cui implicazioni si proiettano sull'incisività della campagna elettorale, sulla capacità di mobilitare consensi e, in definitiva, sul risultato elettorale - risultano peraltro attenuate, almeno in parte, da un tratto che accomuna la vicenda delle principali aggregazioni e fa capo al tipo di sistema elettorale impiegato. Nel quadro di una competizione a turno unico, il processo coalizionale ha teso infatti a antagonizzare $i$ rapporti fra i partner di schieramento (anziché a «neutralizzarli», affidandone le sorti al pronunciamento degli elettori, com'è invece prerogativa del doppio turno) e a esasperare il potere di ricatto delle componenti minori le quali, avendo meno da perdere da un eventuale mancato accordo, detenevano le «chiavi della sconfitta». Si spiegano così, ad esempio, tanto i costi negoziali pagati, a sinistra, dal Pds, quanto, a destra, il sovradimensionamento della Lega.

Un'ultima osservazione inerente l'operatività delle coalizioni è l'assenza di comportamenti differenziati (delle singole formazioni come degli schieramenti) fra Camera e Senato, a dispetto delle aspettative fondate sulle molte differenze fra i due sistemi elettorali (D'Alimonte e Chiaramonte 1993, 539-544). La tendenza a definire gli accordi di coalizione in base al «pacchetto» complessivo dei collegi (regionali o macroregionali a seconda dei casi), il peso soverchiante della logica di schieramento, la necessità dei contendenti di semplificare le scelte strategiche, evitando di renderle eccessivamente sofisticate e quindi più difficilmente governabili e meno facilmente «comunicabili», sono gli elementi che più probabilemente hanno concorso a tale uniformità. Altrettanto «deludente», infine, è l'analisi delle modalità di collegamento fra candidati e simboli partitici, decisive per la Camera - ai fini dello scorporo e dell'attribuzione dei seggi proporzionali. In proposito, salvo limitate eccezioni ${ }^{28}$, le

${ }^{28} \grave{E}$, ad esempio, il caso dell'aggregazione di centro che adotta il collegamento dissociato dei candidati (fatti riferire alla lista del Ppi o alla lista del Patto Segni per lo più in corrispondenza dell'appartenenza del candidato ma nel caso di alcune regioni per l'assenza della lista del Patto Segni), per ragioni legate a un'equa distribuzione dello scorporo (eventuale, ma nel caso specifico assai improbabile). A destra, infatti, i candidati si presentano collegati, nella larga maggioranza dei casi, alle componenti principali di schieramento (la Lega, Forza Italia e Alleanza nazionale) - le sole a aver presentato liste per il riparto dei seggi proporzionali della Camera - con un ulteriore costo per 
TAB. 9. Dentro le coalizioni elettorali: condizioni e modalità della regolazione

\begin{tabular}{|c|c|c|c|}
\hline & Sinistra & Destre & Centro \\
\hline $\mathrm{n}^{\circ}$ attori rilevanti & alto & basso & basso \\
\hline sede negoziale prevalente & livello regionale & livello centrale & $\begin{array}{l}\text { livello regionale } \\
\text { (centralizzato) }\end{array}$ \\
\hline $\begin{array}{l}\text { grado di centralizzazione } \\
\text { decisionale }\end{array}$ & medio & $\begin{array}{c}\text { alto } \\
\left(\text { con eccezioni) }\left(^{\star}\right)\right.\end{array}$ & medio-alto \\
\hline estensione dell'accordo & nazionale & macroregionale & nazionale \\
\hline $\begin{array}{l}\text { grado di uniformità } \\
\text { coalizionale }\end{array}$ & alto & basso & alto \\
\hline grado conflittualità negoziale & alto & $\begin{array}{c}\text { basso } \\
\text { (con eccezioni) }\end{array}$ & medio \\
\hline processo decisionale & lento & rapido & medio \\
\hline criterio di regolazione & $\begin{array}{l}\text { oporzionalizzazion } \\
\text { dell'accordo }\end{array}$ & $\begin{array}{l}\text { e distribuzione or } \\
\text { compensativa }\end{array}$ & $\begin{array}{l}\text { rganizzazione e rapporti } \\
\text { di forza regionali }\end{array}$ \\
\hline
\end{tabular}

(*) Nel Polo del buon governo.

technicalities del meccanismo elettorale sembrano aver largamente prevalso sull'investimento strategico degli attori che, interamente assorbito dalla trattativa relativa ai collegi uninominali, si è ridotto a poca cosa.

\section{Una struttura competitiva a geografia variabile}

$\mathrm{Si}$ è fatto fin qui riferimento ai principali attori della competizione uninominale (i Progressisti a sinistra, il Polo delle libertà e il Polo del buon governo a destra, il Patto per l'Italia al centro), isolandone la fase genetica e gli assetti interni. In questa sezione conclusiva tali attori vengono invece considerati nella loro combinazione d'insieme, congiuntamente ai molti altri

Forza Italia, in particolare al Nord dove la formazione di Berlusconi era largamente sottorappresentata rispetto alla Lega. A sinistra, invece, si segnala il caso della Liguria, dove al tavolo regionale si decide il collegamento «secco» sulla base dell'appartenenza dei candidati. 
pure presenti, con differenziata distribuzione territoriale, nei collegi uninominali. Lo scopo è fissare i principali elementi strutturali dell'offerta elettorale del marzo 1994, la cui configurazione appare peculiare per più rispetti.

Un primo aspetto di ordine generale, che si rende evidente a un'analisi di tipo quantitativo, è la mancata contrazione dell'offerta. Le tabelle 10 (Camera) e 11 (Senato) riportano, a questo riguardo, un riepilogo per area, in cui sono riportati la distribuzione dei collegi in base al numero di candidati, il numero complessivo dei candidati e il numero medio di candidati per collegio. Questi dati possono fornire indicazioni soltanto impressionistiche dell'effettivo formato della competizione, sul quale incide in modo decisivo il grado di competitività delle singole candidature. Se ne ricavano però ugualmente elementi meritevoli di attenzione, soprattutto perché evidenziano fenomeni in buona parte inattesi. Il grado di frammentazione dell'offerta, ad esempio, risulta maggiore al Senato rispetto alla $\mathrm{Ca}$ mera e si presenta inoltre particolarmente elevato nei collegi senatoriali del Nord (in più della metà dei quali sono in lizza nove o dieci candidati). A cosa si deve questo differenziato livello di frammentazione? E come spiegarne la connotazione geografica?

Le variazioni fra Senato e Camera in termini di frammentazione dell'offerta e la maggiore propensione a candidarsi nei collegi senatoriali sembrano dipendere, in generale, dalla diversificata struttura degli incentivi incorporata nelle due leggi elettorali. Non si tratta, evidentemente, di una maggiore o minore facilità di conseguire il seggio, bensì di aspetti relativi alle modalità di presentazione delle candidature o a altre specifiche caratteristiche del meccanismo elettorale (ad esempio la normativa del rimborso delle spese elettorali ${ }^{29}$ ). Rispetto alle condizioni della competizione, all'identità della formula del successo (il conseguimento della maggioranza semplice) corripondono infatti soltanto la diversa grandezza demografica dei collegi (grosso

29 Anche a questo proposito, la normativa per il Senato presenta un'accessibilità maggiore. Il fondo per il rimborso delle spese elettorali è, nel caso della camera alta, a base regionale (anziché nazionale come per la camera bassa) ed è reso disponibile ai gruppi di candidati che abbiano ottenuto almeno un eletto o almeno il $5 \%$ dei voti validi nella regione (anziché il $4 \%$ su scala nazionale o almeno il $3 \%$ e un eletto in sede di collegio uninominale), nonché ai candidati indipendenti che abbiano superato il $15 \%$ dei voti validi su scala regionale (art. 9 della legge 515 del 10 dicembre 1993). 
modo doppia nel caso del Senato rispetto alla Camera) e la diversa estensione anagrafica dell'elettorato attivo (sette classi di età in meno nel caso del Senato). Molteplici, invece, sono le differenze sul fronte della presentazione delle candidature, e tali da rendere per il Senato meno gravose e complesse le operazioni necessarie. La scheda unica, ad esempio, consente di evitare il rompicapo dei collegamenti e la conseguente dispersione dell'attenzione strategica su due livelli distinti (le candidature uninominali nei collegi, le liste nella circoscrizione: con relativa doppia raccolta di firme) com'è invece per la Camera. L'adozione di una pluralità di livelli (circoscrizionali) anziché di un unico livello (nazionale) per l'attribuzione dei seggi proporzionali va nella stessa direzione. Se il minor numero di seggi in palio rende la soglia di rappresentanza (circoscrizionale) in generale più elevata del $4 \%$ previsto (ma su scala nazionale) per la $\mathrm{Ca}$ mera - eccezion fatta per le regioni demograficamente più gran$\mathrm{di}^{30}$-, le scelte relative si configurano tuttavia come una somma di strategie regionali, percorribili anche singolarmente e quindi accessibili anche per attori minori, a radicamento soltanto bcale e dotati di scarse risorse organizzative. Al Senato, ma non alla Camera, è infine possibile candidarsi - dopo aver raccolto un numero di firme compreso fra le 1.000 e le 1.500 , ridotto alla metà in caso di elezioni anticipate - come candidati indipendenti e quindi non collegati a alcun gruppo su scala regionale (e pertanto esclusi dal riparto proporzionale).

La diversa entità della soglia di entrata nell'arena elettorale, connessa alla regionalizzazione del meccanismo elettorale del Senato, spiega dunque il diverso grado di frammentazione dell'offerta fra camera alta e camera bassa. Quanto alla connotazione geografica del fenomeno, $\mathrm{e}$ in particolare al maggiore sventagliamento delle candidature che si riscontra nei collegi senatoriali del Nord, si tratta di un esito dovuto alla concomitan$\mathrm{za}$, in quei collegi, di tutti i fattori che concorrono alla frammentazione: l'intersecarsi dei poli a destra, la presenza di candidature collegate a formazioni nazionali escluse o marginali rispetto al gioco coalizionale e di candidature espressione di movimenti a carattere localistico, il concorso di candidature indi-

${ }^{30}$ In Lombardia, ad esempio, risultano infatti eletti in quota proporzionale un candidato della Lista Pannella, con il 3,8\% dei voti validi su scala regionale (e il $2,3 \%$ su scala nazionale), e un candidato della Lega alpina lumbarda, con il $4,3 \%$ dei voti validi su scala regionale (e lo $0,7 \%$ su scala nazionale). 
pendenti, sciolte da collegamenti su scala regionale. Un'articolazione così ampia dell'offerta elettorale in un'area, come la maggior parte dei collegi del Nord, a elevata territorializzazione (attesa) del voto condannava in partenza la maggior parte di tali candidature a un ruolo esclusivamente decorativo. La relativa facilità d'accesso alla candidatura e la specificità delle condizioni ambientali hanno però impedito che la prospettiva di un sicuro insuccesso si trasformasse in un deterrente sufficiente a scoraggiare forze minori e candidati senza speranze.

Le tabelle 10 e 11 recano anche le variazioni territoriali della distribuzione dei collegi in classi definite dal numero dei candidati che vi concorrono. Le differenze che anche a questo proposito si riscontrano nelle tre aree considerate sono indicative del grado di compattezza o, al contrario, della rarefazione dell'offerta nei collegi uninominali di una stessa area macroregionale. A riguardo si segnala soprattutto, per la Camera, lo scarto fra zona rossa e Nord, da un lato, e Sud, dall'altro, nonostante un numero medio di candidati per collegio pressoché analogo. Nei primi due casi l'offerta elettorale è piuttosto compatta e quasi il $90 \%$ dei collegi conta quattro o cinque candidati. Nel

TAB. 10. Camera dei deputati. Distribuzione dei collegi in base al numero di candidati e formato competitivo medio. Aggregazione per area geo-politica (Nord, zona rossa, Sud)

\begin{tabular}{|c|c|c|c|c|c|c|c|c|}
\hline \multirow[b]{2}{*}{$N$ candidati } & \multicolumn{2}{|l|}{ Nond } & \multicolumn{2}{|c|}{ Zona rossa } & \multicolumn{2}{|l|}{ Sud } & \multicolumn{2}{|l|}{ Italia } \\
\hline & $\mathrm{N}$ collegi & $\%$ & $\mathrm{~N}$ collegi & $\%$ & $\mathrm{~N}$ collegi & i \% & $\mathrm{N}$ collegi & $\%$ \\
\hline 2 & 1 & 0,6 & - & & 4 & 1,9 & 5 & 1,5 \\
\hline 3 & 2 & 1,1 & 10 & 12,5 & 35 & 16,3 & 47 & 9,9 \\
\hline 4 & 105 & 58,3 & 44 & 55,0 & 59 & 27,4 & 208 & 43,8 \\
\hline 5 & 60 & 33,3 & 22 & 27,5 & 67 & 31,1 & 149 & 31,4 \\
\hline 6 & 12 & 6,7 & 3 & 3,75 & 35 & 16,3 & 50 & 10,5 \\
\hline 7 & - & & 1 & 1,25 & 8 & 3,7 & 9 & 1,9 \\
\hline 8 & - & & - & & 5 & 2,3 & 5 & 1,1 \\
\hline 9 & - & & - & & 2 & 0,9 & 2 & 0,4 \\
\hline tot. & 180 & 100,0 & 80 & 100,0 & 215 & 100,0 & 475 & 100,0 \\
\hline $\mathrm{N}$ candidati & \multicolumn{2}{|c|}{800} & \multicolumn{2}{|c|}{341} & \multicolumn{2}{|c|}{1.008} & \multicolumn{2}{|c|}{2.149} \\
\hline formato medio & \multicolumn{2}{|c|}{4,4} & \multicolumn{2}{|c|}{4,3} & \multicolumn{2}{|r|}{4,7} & \multicolumn{2}{|c|}{4,5} \\
\hline
\end{tabular}

Fonte: Elaborazione sui dati del Servizio elettorale del Ministero degli Interni. 
TAB. 11. Senato della Repubblica. Distribuzione dei collegi in base al numero di candidati e formato competitivo medio. Aggregazione per area geo-politica (Nord, zona rossa, Sud)

\begin{tabular}{|c|c|c|c|c|c|c|c|c|}
\hline \multirow[b]{2}{*}{$\mathrm{N}$ candidati } & \multicolumn{2}{|c|}{ Nord } & \multicolumn{2}{|c|}{ Zona rossa } & \multicolumn{2}{|c|}{ Sud } & \multicolumn{2}{|c|}{ Italia } \\
\hline & $\mathrm{N}$ collegi & $\%$ & $N$ collegi & $\%$ & $\mathrm{~N}$ colleg & i $\%$ & $\mathrm{~N}$ collegi & $\%$ \\
\hline 3 & - & & 5 & 12,5 & 4 & 3,8 & 9 & 3,9 \\
\hline 4 & 3 & 3,4 & 6 & 15,0 & 16 & 15,2 & 25 & 10,8 \\
\hline 5 & 13 & 14,9 & - & & 30 & 28,6 & 43 & 18,5 \\
\hline 6 & 3 & 3,4 & 24 & 60,0 & 35 & 33,3 & 62 & 26,7 \\
\hline 7 & 13 & 14,9 & 5 & 12,5 & 17 & 16,2 & 35 & 15,1 \\
\hline 8 & 8 & 9,2 & - & & 3 & 2,8 & 11 & 4,7 \\
\hline 9 & 44 & 50,6 & - & & - & & 44 & 19,0 \\
\hline 10 & 3 & 3,4 & - & & - & & 3 & 1,3 \\
\hline tot. & 87 & 100,0 & 40 & 100,0 & 105 & 100,0 & 232 & 100,0 \\
\hline $\mathrm{N}$ candidati & \multicolumn{2}{|c|}{676} & \multicolumn{2}{|c|}{218} & \multicolumn{2}{|c|}{579} & \multicolumn{2}{|c|}{1.473} \\
\hline formato medio & \multicolumn{2}{|c|}{7,8} & \multicolumn{2}{|c|}{5,4} & \multicolumn{2}{|c|}{5,5} & \multicolumn{2}{|r|}{6,3} \\
\hline
\end{tabular}

Fonte: Elaborazione sui dati del Servizio elettorale del Ministero degli Interni.

Sud, invece, il formato è assai più «sgranato», il che indica una minore omogeneità della struttura competitiva - di cui si è già esaminato un primo importante elemento causale: le circoscrizioni a Polo del buon governo diviso -, nonché, probabilmente, un maggior grado di «apertura» della competizione.

Questo quadro quantitativo può essere meglio precisato se si passano a considerare alcuni tratti qualitativi delle candidature. Due aspetti - il profilo politico di base e il grado di rilevanza competitiva potenziale di tali candidature - appaiono utili, almeno in prima battuta, a definire alcune caratteristiche tipologiche delle 3.622 candidature ( 1.473 per il Senato e 2.149 per la Camera).

La connotazione partitica o personalistica delle candidature, da un lato, e la loro diffusione territoriale, dall'altro, consentono di fissare il profilo politico di base dei candidati. In termini territoriali, la distinzione si pone fra candidature a estensione pluricircoscrizionale, candidature di ambito regionale, candidature limitate a un solo collegio (o a pochi collegi di una stessa circoscrizione). Le prime sono connotate in senso partitico e identificano attori di impianto nazionale o macroregionale. Si tratta, anzitutto, delle candidature delle quattro aggregazioni 
elettorali, la cui presenza definisce nella maggior parte dei collegi un formato competitivo di base a carattere trinario ${ }^{31}$, ma anche di candidature mono-partitiche quali Pannella-Riformatori o, nei collegi del Nord e della zona rossa, Alleanza nazionale. In questo novero possono essere comprese pure le candidature di formazioni minori - ad esempio Pensionati, Socialdemocrazia, Partito della legge naturale - presenti, in ordine sparso, in più circoscrizioni. Le candidature regionali e quelle limitate a uno o pochi collegi sono entrambe a radice locale. Mentre però le ultime sono per definizione a connotazione personalistica, le prime possono essere anche a carattere partitico e fare riferimento a formazioni e movimenti localistici. È il caso, ad esempio, delle candidature Svp nell'Alto Adige, di quelle sardiste, di quelle collegate alle leghe territoriali presenti in Lombardia e in Veneto, ma anche in Piemonte, Liguria e Toscana. Quanto alle candidature a connotazione personalistica, in ambito regionale si registra la presenza di candidature legate a parlamentari uscenti, appartenenti per lo più a $\mathrm{Dc}$ e Psi e in alcuni casi con precedenti responsabilità di governo, i quali promuovono raggruppamenti o (nel caso della Camera) liste d'occasione (è il caso, in Campania, dell'Unione riformista meridionale di Conte, dell'Unione cristiani e riformisti di Facchiano, dell'Unione popolare di Del Mese, presenti anche alla Camera). Più frequente è però il caso delle candidature di collegio - le candidature indipendenti del Senato -, cui si affidano sia alcuni «entranti», sia «uscenti» in difficoltà politiche o giudiziarie (ad esempio Mannino e Nicolosi in Sicilia, Marongiu e Lettieri in Basilicata, Marcucci in Toscana e altri).

Il secondo aspetto qualitativo - la rilevanza competitiva potenziale delle candidature - investe non solo la loro credibile possibilità di successo - possibilità circoscritta in generale, secondo combinazioni territoriali di vario tipo, alle aggregazioni esaminate nelle sezioni precedenti - ma anche la loro capacità di influenzare il successo o la sconfitta altrui. Se, in tal senso, tutti i candidati si vedono attribuita una qualche rilevanza competitiva - se è vero, come è vero, che in una competizione a sistema maggioritario semplice, il numero dei competitori è una delle variabili che determina la soglia di elezione (Rae 1971) -,

${ }^{31} \mathrm{Si}$ osservi nelle tabelle 10 e 11 come siano soltanto cinque i collegi (della Camera) a competizione binaria. 


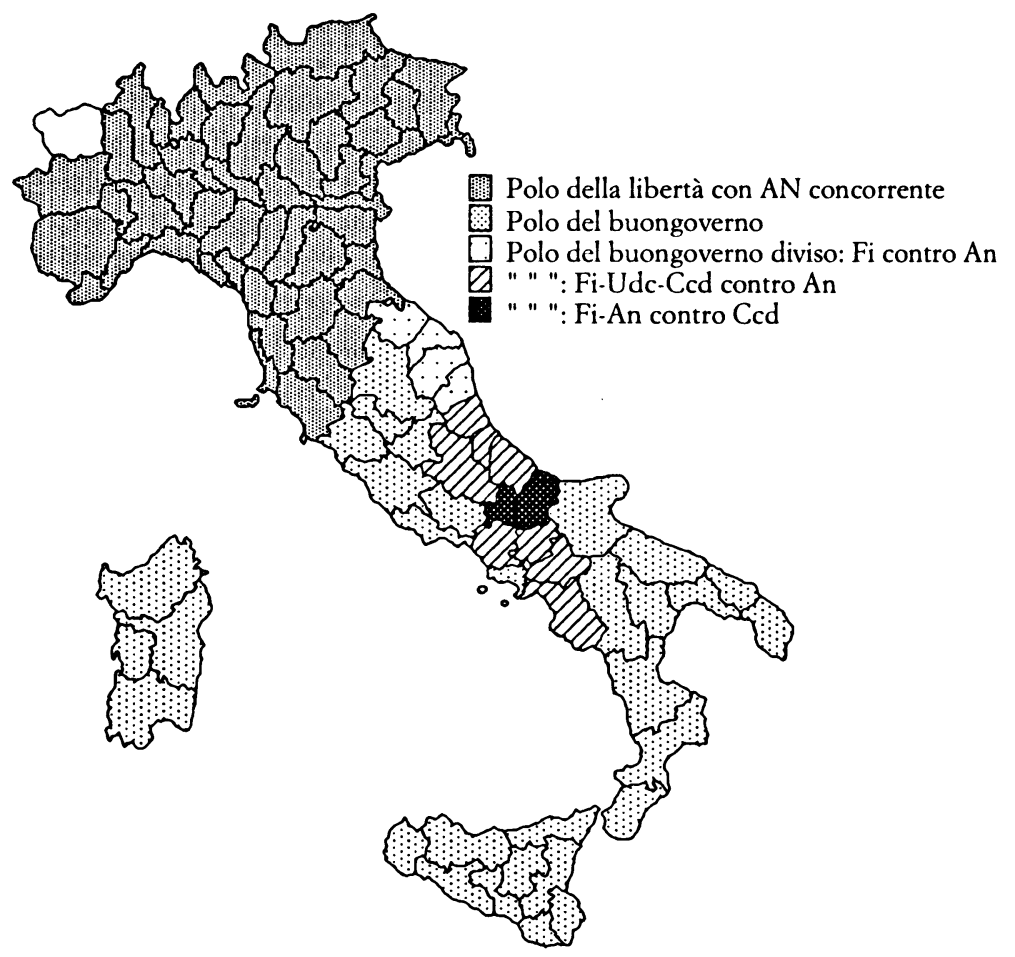

FIG. 1a. La geografia dell'offerta delle destre: Camera dei Deputati

è pur sempre possibile distinguerne il grado e differenziare fra candidature «competitive» in senso stretto, candidature rilevanti pur se «marginali» e candidature decisamente «residuali».

Se sulla scorta del quadro analitico così definito torniamo al caso concreto, ci si trova a confronto con un insieme di situazioni complesso e territorialmente assai articolato. Il caso singolo di maggior rilevanza, sia per il suo significato politico sia per le sue conseguenze sulla struttura della competizione elettorale, è quello dello schieramento di destra (Figg. 1a e 1b). La formazione di due aggregazioni macroregionali, «nazionalizzate» dalla presenza in entrambe di Forza Italia, munisce tale schieramento di una capacità competitiva altrimenti assai più aleatoria. Le specifiche modalità dell'intesa - lo si è già detto - ne limitano però le potenzialità competitive. Nel Nord, lo schieramento di 


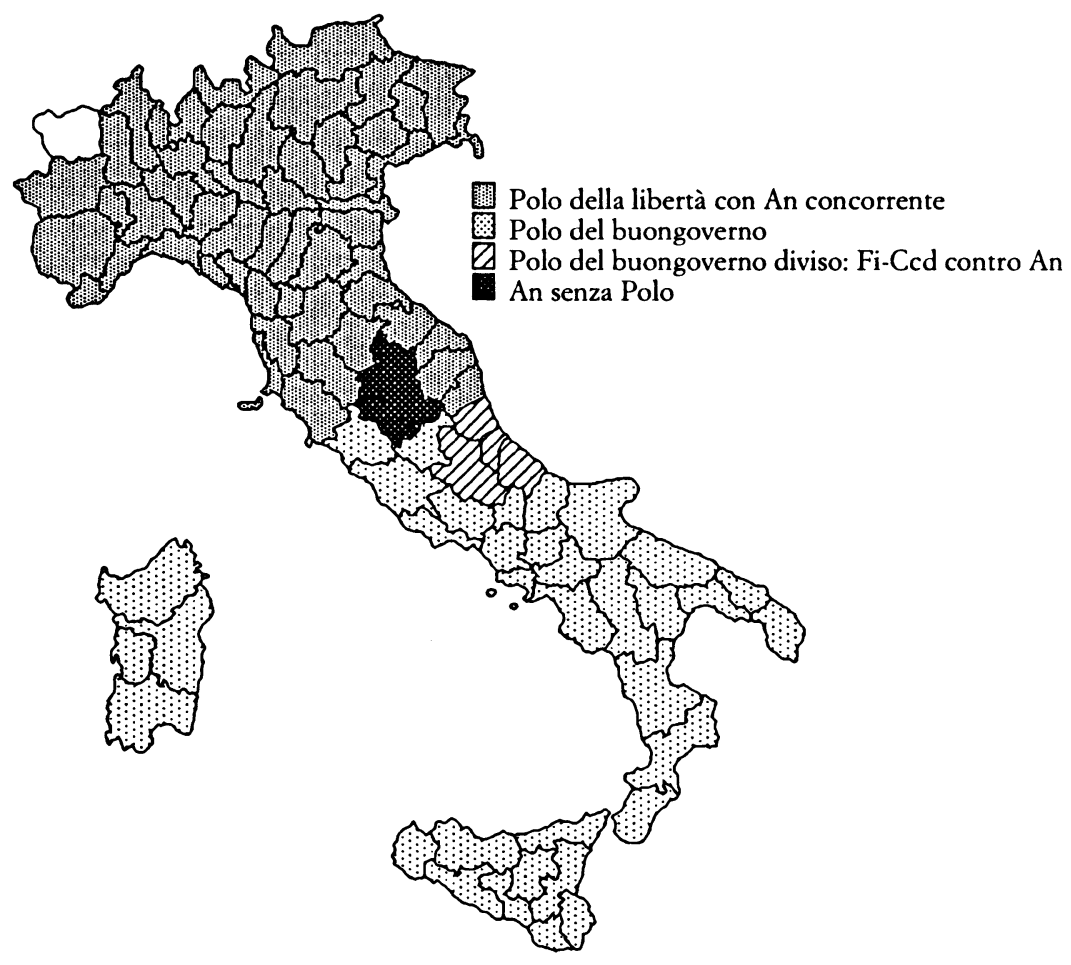

FIG. 1b. La geografia dell'offerta delle destre: Senato della Repubblica

destra presenta infatti due candidati per collegio (il candidato del Polo delle libertà e quello di Alleanza nazionale). Nella zona rossa, dove corre la frontiera fra i due poli e dove le chances elettorali dello schieramento di destra si presentavano assai modeste, la coerenza è ancora minore. Il Polo delle libertà, ad esempio, «scende» fino alle Marche, ma solo nei collegi senatoriali, mentre non è presente in Umbria. Il Polo del buon governo trova in Umbria la sua esposizione più settentrionale, ma solo per la Camera, in quanto nei collegi senatoriali di quella stessa circoscrizione lo schieramento è rappresentato in via esclusiva da Alleanza nazionale, che corre da sola anche nei collegi marchigiani per la Camera, in questo caso però in concorrenza con Forza Italia. Situazioni di divisione, con conseguente «duplicazione» delle candidature, si presentano infine nei colle- 
gi del Mezzogiorno, in particolare alla Camera, secondo un'articolazione il cui dettaglio è riportato nella figura $1 \mathrm{a}$.

Quanto alle coordinate complessive dell'offerta, è possibile ricondurle (come nelle tabelle $12 \mathrm{a}$ e $12 \mathrm{~b}$ in riferimento a quattro circoscrizioni esemplari) a quattro tipi di candidature - $(a)$ partitiche nazionali o macroregionali, $(b)$ partitiche regionali, $(c)$ personalistiche regionali, $(d)$ individuali - disposte lungo tre livelli di rilevanza competitiva potenziale (candidature competitive, marginali, residuali).

Nel primo livello si collocano essenzialmente le candidature partitiche espresse dalle aggregazioni esaminate da vicino in questo lavoro. In molti collegi, in particolare nel Nord e nella zona rossa, i candidati del Patto per l'Italia sembravano peraltro condannati a giocare per lo più il tipico ruolo del «terzo partito», dotato (come nel caso dei liberali britannici) di un consenso territorialmente diffuso, ma destinato a rimanere sotto-maggioritario nei singoli collegi (pur se magari decisivo per l'attribuzione del seggio). Ai candidati dei poli si aggiungono in questa casella le candidature partitiche a forte radicamento territoriale e a tradizionale concentrazione sovra-maggioritaria (candidature Svp in Alto Adige).

Il secondo livello comprende candidature partitiche quali Pannella-Riformatori (una delle molte varianti della strategia anfibia cui il leader radicale si è ispirato a dispetto delle dichiarate simpatie «anglosassoni» e in cui hanno trovato spazio, oltre alle avventure solitarie, la partecipazione a aggregazioni con vocazione maggioritaria, la desistenza nei collegi e la presentazione di liste proprie per la competizione proporzionale della $\mathrm{Ca}$ mera) e Alleanza nazionale al Nord e nelle regioni rosse, ma anche candidature di outsider a radice locale, concorrenti in collegamento con movimenti ad boc o presenti come candidati indipendenti.

Per tutte le altre candidature (a connotazione personalistica o collegate con movimenti politici localistici; regionali o di collegio) il grado di rilevanza competitiva potenziale è del tutto residuale, in particolare nel caso delle candidature eteroclite e cartacee, e spesso «impolitiche», degli «entranti» in corsa come indipendenti al Senato.

La configurazione dell'offerta, e la struttura della competizione che ne deriva, denota, in conclusione, un processo di socializzazione degli attori alle nuove regole di voto ancora incompiuto e un processo di apprendimeno ancora insufficiente. 
TAB. 12a. Tipologia delle candidature: Lombardia, Toscana, Campania, Abruzzo. Camera dei deputati

\begin{tabular}{|c|c|c|c|c|}
\hline & $\begin{array}{l}\text { Lombardia } \\
\text { (74 collegi) }\end{array}$ & $\begin{array}{l}\text { Toscana } \\
\text { ( } 29 \text { collegi) }\end{array}$ & $\begin{array}{l}\text { Abruzzo } \\
\text { (11 collegi) }\end{array}$ & $\begin{array}{l}\text { Campania } \\
\text { (47 collegi) }\end{array}$ \\
\hline \multicolumn{5}{|c|}{ Candidature competitive: } \\
\hline I & $\begin{array}{l}\text { Progressisti }(74) \\
\text { Polo delle libertà }(74) \\
\text { Patto per l'Italia (72) }\end{array}$ & $\begin{array}{l}\text { Progressisti (29) } \\
\text { Polo delle libertà (27) } \\
\text { Patto per l'Italia (29) }\end{array}$ & $\begin{array}{l}\text { Progressisti (11) } \\
\text { Alleanza nazionale (11) } \\
\text { Forza Italia-Ccd (11) } \\
\text { Patto per l'Italia (11) }\end{array}$ & $\begin{array}{l}\text { Progressisti (47) } \\
\text { Polo del buongoverno (25) } \\
\text { Patto per l'Italia (47) } \\
\text { Alleanza nazionale (22) } \\
\text { Forza Italia-Ccd (22) }\end{array}$ \\
\hline \multicolumn{5}{|c|}{ Candidature marginali: } \\
\hline I & $\begin{array}{l}\text { Pannella-Riformatori (23) } \\
\text { Alleanza nazionale ( } 73 \text { ) }\end{array}$ & $\begin{array}{l}\text { Pannella-Riformatori (14) } \\
\text { Alleanza nazionale (29) } \\
\text { Socialdemocrazia (1) }\end{array}$ & & Pannella-Riformatori (23) \\
\hline II & Lega Alpina lumbarda (1) & & & \\
\hline II & & & & $\begin{array}{l}\text { Un. Rif. mer. (4) } \\
\text { Un. Pop. (6) } \\
\text { Un. Crist. Rif. (11) }\end{array}$ \\
\hline IV & & Insieme sviluppo (1) & Soc.lib.dem.pop (1) & \\
\hline
\end{tabular}


TAB. 12a. (segue)

\begin{tabular}{llll}
\hline $\begin{array}{l}\text { Lombardia } \\
(74 \text { collegi })\end{array}$ & $\begin{array}{l}\text { Toscana } \\
(29 \text { collegi })\end{array}$ & $\begin{array}{l}\text { Abruzzo } \\
(11 \text { collegi })\end{array}$ & $\begin{array}{l}\text { Campania } \\
(47 \text { collegi })\end{array}$ \\
\hline
\end{tabular}

Candidature residuali:

II

IV
Rinnovamento (2)

Partito di centro (1)

\section{Lista fittizia (2) \\ Rinascita socialista (1) \\ P. per la libertà (1)}

Programma Italia (6)

Socialdemocrazia (8)

Alleanza Meridionale (8)

Unione mediterranea (2)

Unione dem. riform. (1)

All. Municipalità (3)

Insieme per cambiare (1)

Abruzzo lib-soc (1)

Liberali (1)
Coaliz.Arcobaleno (1)

L'Arca (4)

Alleanza vesuviana (2)

Alleanza pop. (1)

Solidarietà dem. (1)

Unione dem. (2)

$\mathrm{XXV}$ ora (1)

Un. pop. (9)

Unione Dem. It. (7)

Riformisti irpini (3)

La nostra terra (2)

Mov. Crist. europeo (1)

I: candidature partitiche nazionali o macroregionali

II: candidature partitiche di ambito regionale

III: candidature di ambito regionale a connotazione personalistica

IV: candidature individuali o limitate a pochi collegi di un'unica circoscrizione. 
TAB. 12b. Tipologia delle candidature: Lombardia, Toscana, Campania, Abruzzo. Senato della Repubblica

\begin{tabular}{|c|c|c|c|c|}
\hline & $\begin{array}{l}\text { Lombardia } \\
\text { (35 collegi) }\end{array}$ & $\begin{array}{l}\text { Toscana } \\
\text { (14 collegi) }\end{array}$ & $\begin{array}{l}\text { Abruzzo } \\
\text { ( } 5 \text { collegi) }\end{array}$ & $\begin{array}{l}\text { Campania } \\
(22 \text { collegi) }\end{array}$ \\
\hline \multicolumn{5}{|c|}{ Candidature competitive: } \\
\hline I & $\begin{array}{l}\text { Progressisti (35) } \\
\text { Polo delle libertà (35) } \\
\text { Patto per l'Italia (35) }\end{array}$ & $\begin{array}{l}\text { Progressisti (14) } \\
\text { Polo delle libertà (14) } \\
\text { Patto per l'Italia (14) }\end{array}$ & $\begin{array}{l}\text { Progressisti (5) } \\
\text { Alleanza nazionale (5) } \\
\text { Forza Italia-Ccd (5) } \\
\text { Patto per l'Italia (5) }\end{array}$ & $\begin{array}{l}\text { Progressisti (22) } \\
\text { Polo del buongoverno(22) } \\
\text { Patto per l'Italia (22) }\end{array}$ \\
\hline \multicolumn{5}{|c|}{ Candidature marginali: } \\
\hline I & $\begin{array}{l}\text { Pannella-Riformatori (35) } \\
\text { Alleanza nazionale ( } 35) \\
\text { Partito pensionati (35) }\end{array}$ & $\begin{array}{l}\text { Pannella riformatori (14) } \\
\text { Alleanza nazionale (14) }\end{array}$ & & \\
\hline II & $\begin{array}{l}\text { Lega Angela Bossi (35) } \\
\text { Lega Alpina lumbarda (13) }\end{array}$ & & & \\
\hline III & & & & $\begin{array}{l}\text { Un. Riform. merid. (4) } \\
\text { Un. Popolare (6) } \\
\text { Un. Crist. e Rif. (12) }\end{array}$ \\
\hline
\end{tabular}


TAB. 12b. (segue)

\begin{tabular}{lllll}
\hline & $\begin{array}{l}\text { Lombardia } \\
(35 \text { collegi) }\end{array}$ & $\begin{array}{l}\text { Toscana } \\
(14 \text { collegi) }\end{array}$ & $\begin{array}{l}\text { Abruzzo } \\
(5 \text { collegi) }\end{array}$ & $\begin{array}{l}\text { Campania } \\
(22 \text { collegi) }\end{array}$ \\
\hline Candidature residuali: & & & & Programma Italia (6) \\
I & Partito legge naturale (35) & & Lega Aut.Toscana (14) & Alleanza Meridionale (8) \\
II & Democratici popolari (3) & $\begin{array}{l}\text { Gervasi (1) } \\
\text { Mov. «Catt. Rinnov.» (1) } \\
\text { Insieme sviluppo (1) }\end{array}$ & $\begin{array}{l}\text { Delfino al Senato (1) } \\
\text { Centro (1) } \\
\text { Pdp (1) } \\
\text { All. Municipalità (1) }\end{array}$ & \\
\hline
\end{tabular}

I: candidature partitiche nazionali o macroregionali

II: candidature partitiche di ambito regionale

III: candidature di ambito regionale a connotazione personalistica

IV: candidature individuali o limitate a pochi collegi di un'unica circoscrizione. 
Fermo restando che la prima volta esercita spesso un'influenza che si protrae nel tempo, la persistenza dei fenomeni esaminati dipenderà in larga parte dai due fattori cui si è fatto riferimento all'inizio del lavoro: il sistema partitico (nella sua evoluzione verso una diversa configurazione di sé) e il sistema elettorale (di cui gli attori hanno dimostrato di aver compreso solo in parte $\mathrm{i}$ meccanismi e di cui però da più parti si reclamano nuove modifiche).

\section{Riferimenti bibliografici}

Bartolini, S. e P. Mair (1985), Identity, competition, and electoral availability, Cambridge, Cambridge University Press.

Butera, F. (1990), Il castello e la rete, Milano, Angeli.

Caciagli, M. e A. Spreafico (1990), Introduzione in M. Caciagli e A. Spreafico (a cura di), Vent'anni di elezioni in Italia. 1968-1988, Padova, Liviana, pp. VII-XXII.

Camera dei deputati (1994), Riaggregazione dei dati elettorali 1992 secondo i nuovi collegi uninominali costituiti con il decreto legislativo n. 536 del 1993, Quaderni di documentazione del servizio studi della Camera.

Corbetta, P., A. Parisi e H. Schadee (1988), Elezioni in Italia. Struttura e tipologia delle consultazioni politiche, Bologna, Il Mulino.

Corrias, P., M. Gramellini, C. Maltese (1994), 1994. Colpo grosso, Milano, Baldini e Castoldi.

D'Alimonte, R. e Chiaramonte, A. (1993), Il nuovo sistema elettorale italiano: quali opportunità?, in "Rivista italiana di scienza politica», XXIII, pp. 513-547.

Del Monte, F. (presentazione a cura di) (1991), Conferimento di laurea bonoris causa in ingegneria gestionale al dott. Silvio Berlusconi, Università degli studi della Calabria, Facoltà di Ingegneria, Arcavacata di Rende, 27 novembre.

Diamanti, I. (1993), La Lega. Geografia, storia e sociologia di un nuovo soggetto politico, Roma, Donzelli.

- (1994), La politica come marketing, in «Micromega», 2, pp. 60-77.

Diamanti, I. e R. Mannheimer (1994), Introduzione, in I. Diamanti e R. Mannheimer (a cura di), Milano a Roma. Guida all'Italia elettorale del 1994, Roma, Donzelli, pp. VII-XXII.

Di Virgilio, A. (1993), Elezioni in Italia, in «Quaderni dell'Osservatorio elettorale», 29, gennaio-giugno, pp. 125-151.

- (1994), Elezioni locali e destrutturazione partitica. La nuova legge alla prova, in «Rivista italiana di scienza politica», XXIV, pp. 107165.

Huntington, S. (1968), Political order in changing societies, New Ha- 
ven e Londra, Yale University Press (trad. it. 1975, Milano, Angeli).

Ignazi, P. (1992), Dal Pci al Pds, Bologna, il Mulino.

Panebianco, A. (1982), Modelli di partito. Organizzazione e potere nei partiti politici, Bologna, il Mulino.

Pappalardo, A. (1994), La nuova legge elettorale in Parlamento: chi come e perché, in «Rivista italiana di scienza politica», XXIV, pp. 287-310.

Rae, D.W. (1971), The political consequences of electoral laws, New Haven, Yale Universiy Press.

Sartori, G. (1994), Poli elettorali? No, ammucchiate, in «Corriere della Sera», 12 febbraio. 